\title{
Light at night and risk of breast cancer: a systematic review and dose-response meta-analysis
}

\author{
Teresa Urbano ${ }^{1} \mathbb{D}$, Marco Vinceti ${ }^{1} 2^{*} \mathbb{D}$, Lauren A. Wise ${ }^{2}$ a and Tommaso Filippini $^{1}$ (D)
}

\begin{abstract}
Breast cancer is the most common malignancy in women and the second leading cause of cancer death overall. Besides genetic, reproductive, and hormonal factors involved in disease onset and progression, greater attention has focused recently on the etiologic role of environmental factors, including exposure to artificial lighting such as light-at-night (LAN). We investigated the extent to which LAN, including outdoor and indoor exposure, affects breast cancer risk. We performed a systematic review of epidemiological evidence on the association between LAN exposure and breast cancer risk, using a dose-response meta-analysis to examine the shape of the relation. We retrieved 17 eligible studies through September 13, 2021, including ten cohort and seven case-control studies. In the analysis comparing highest versus lowest LAN exposure, we found a positive association between exposure and disease risk (risk ratio [RR] 1.11,95\% confidence interval-Cl 1.07-1.15), with comparable associations in case-control studies (RR $1.14,95 \% \mathrm{Cl}$ 0.98-1.34) and cohort studies (RR 1.10, 95\% Cl 1.06-1.15). In stratified analyses, risk was similar for outdoor and indoor LAN exposure, while slightly stronger risks were observed for premenopausal women (premenopausal: RR 1.16, 95\% Cl 1.04-1.28; postmenopausal: 1.07, 95\% Cl 1.02-1.13) and for women with estrogen receptor (ER) positive breast cancer (ER+: RR 1.09, 95\% Cl 1.02-1.17; ER-: RR 1.07, 95\% Cl 0.92-1.23). The dose-response meta-analysis, performed only in studies investigating outdoor LAN using comparable exposure assessment, showed a linear relation up to $40 \mathrm{nW} / \mathrm{cm}^{2} / \mathrm{sr}$ after which the curve flattened, especially among premenopausal women. This first assessment of the dose-response relation between LAN and breast cancer supports a positive association in selected subgroups, particularly in premenopausal women.
\end{abstract}

Keywords: Breast cancer, Light-at-night, Lighting, Menopausal status, Dose-response meta-analysis

\section{Introduction}

Breast cancer is the most common cancer in women in both developed and undeveloped countries [1]. In Italy, there were an estimated 55,000 new cases in 2020 [2], and while incidence is increasing, mortality rates have significantly decreased across the years. Several factors appear to be involved in both etiology and prognosis of

\footnotetext{
*Correspondence: marco.vinceti@unimore.it

${ }^{1}$ CREAGEN - Environmental, Genetic and Nutritional Epidemiology Research Center, Department of Biomedical, Metabolic and Neural Sciences, University of Modena and Reggio Emilia, Modena, Italy Full list of author information is available at the end of the article
}

this malignancy, including selected genes, ageing, family history, reproductive factors, long-term use of postmenopausal female hormones, lifestyle [3, 4], and environmental factors such as exposure to chemical endocrine disruptors [5-9].

In 2007, the International Agency for Research on Cancer (IARC) defined night-shift work as 'probably carcinogenic to humans' i.e. belonging to category 2A [10], due to a possible link with breast cancer [11, 12] and with prostate and colorectal cancer [13]. The definition of night-shift work, also identified as graveyard shift, refers to a work schedule involving the sleeping hours of original author(s) and the source, provide a link to the Creative Commons licence, and indicate if changes were made. The images or other third party material in this article are included in the article's Creative Commons licence, unless indicated otherwise in a credit line to the material. If material is not included in the article's Creative Commons licence and your intended use is not permitted by statutory regulation or exceeds the permitted use, you will need to obtain permission directly from the copyright holder. To view a copy of this licence, visit http://creativecommons.org/licenses/by/4.0/. The Creative Commons Public Domain Dedication waiver (http://creativeco mmons.org/publicdomain/zero/1.0/) applies to the data made available in this article, unless otherwise stated in a credit line to the data. 
the general population. Among the exposure linked to graveyard shift work there is light-at-night (LAN), which induces disruption of the circadian rhythm and oxidative stress [14]. In particular, LAN could be involved in breast cancer etiology through different mechanistic pathways including DNA damage, impairment of melatonin and estrogen secretion, inflammation, and disruption of metabolic function [15]. Exposure to LAN can cause circadian and sleep disruptions, which may adversely affect different inflammatory and immunological pathways, thereby decreasing production of circulating natural killer cells or enhancing pro-inflammatory effects [16, 17]. Since sleep has antioxidant effects, its disruption may also cause increased production of reactive oxygen species $[18,19]$. When evaluating exposure to LAN, both outdoor (e.g., streetlamps, illuminated buildings, lights from vehicles) and indoor artificial sources (e.g., domestic lights, electric devices-derived illumination) are relevant in increasing circadian disruption and therefore the risk of developing cancer. Outdoor LAN is generally assessed using satellite-derived data, while indoor is often evaluated through surveys on night habits and bedroom light characteristics [20].

Two recent meta-analyses summarized data on the association between LAN and breast cancer risk, investigating the effects of the highest vs. the lowest LAN exposure categories [21, 22]. Since the publication of these meta-analyses, three large studies of the LAN-breast cancer association have been published [23-25]. In the present report, we update the meta-analysis with these new studies, perform subgroup analyses by breast cancer subtype and other factors, and more comprehensively assess the epidemiological evidence about LAN and breast cancer risk. In addition, we apply dose-response metaanalyses to assess, for the first time, the shape of the association between LAN and breast cancer.

\section{Methods}

We followed the Preferred Reporting Items for Systematic Reviews and Meta-Analysis (PRISMA) 2020 statement [26] to perform this review.

\section{Study identification and selection}

The research question was configured according to PECOS statement (Population, Exposure, Comparator(s), Outcomes, and Study design): "Is exposure to light-atnight, as assessed through indoor and outdoor exposure to lighting sources, positively associated with risk of breast cancer in non-experimental studies?" and "Is there a dose-response association between LAN and breast cancer incidence?" [27]. Accordingly, we carried out a systematic literature search for publications available as of September 13, 2021 in the PubMed/MEDLINE,
Embase and Web of Science (WoS) databases. We used search terms linked to "breast cancer" and "lighting" in PubMed, WoS, and Embase databases with no language restrictions (Additional file 1: Table S1). We also performed citation chasing by scanning the reference list of included studies and of previous reviews, as well as backward/forward citation retrieval to identify additional relevant papers [28]. Inclusion criteria were as follows: titles including LAN and breast cancer; mentioning case-control/case-cohort/cohort studies; monitoring LAN from space according to the US Defense Meteorological Satellite Program (DMSP) Operational Linescan System or from the Visible Infrared Imaging Radiometer Suite Day-Night Band (DNB); evaluating indoor LAN based on self-reported questionnaires and mentioning LAN levels as low, medium or high, and darkness and nightlight levels, and habits of sleeping with lights on; reporting of risk estimates for breast cancer, along with their 95\% confidence intervals, or availability of enough data to calculate them.

Two authors reviewed all titles and abstracts independently, and any conflicts were resolved with the help of third author. For each included study, we extracted information about design, population size and characteristics, country, study period and years of follow-up, risk estimates (either odds ratio, risk ratio, or hazard ratio) along with their 95\% confidence interval (CI) of breast cancer, adjustment factors, type of exposure assessment, and dose of exposure.

\section{Quality assessment}

We assessed the quality in the included studies by using the Risk Of Bias In Non-randomized Studies of Exposures (ROBINS-E) tool [29]. We classified studies as having low, moderate, or high risk of bias according to seven domains: bias due to confounding; bias in selecting participants in the study; bias in exposure classification; bias due to departures from intended exposures; bias due to missing data; bias in outcome measurement; and bias in the selection of reported results. In Additional file 1: Table S2, we report criteria for risk of bias evaluation, performed by two authors. In case of disagreement, a third author helped in the final decision. A study's overall risk of bias was considered high or moderate if at least one domain was judged at high or moderate risk, otherwise it was classified as having a low risk of bias.

\section{Statistical analysis}

We performed a meta-analysis comparing breast cancer incidence in the highest versus lowest levels of LAN exposure using a restricted maximum likelihood random effect model, which bases estimates on a likelihood function calculated from a transformed set of data [30]. 
Additionally, whenever possible, we carried out a doseresponse meta-analysis of breast cancer risk according to increasing LAN exposure through a random-effects model, using a one-stage approach as previously implemented in other fields [31-33]. Specifically, for each LAN category, we used the mean or the median value, or the midpoint for the intermediate categories, whichever was available. For the highest and lowest exposure categories, if the average values were not reported and were 'open', we used as boundary a value $20 \%$ higher or lower than the closest cut-point. We used a restricted cubic spline model with three knots at fixed percentiles (10th, 50th, and 90th) and we considered the correlation within each set of published effect estimates using generalized leastsquares regression through a multivariate random-effect meta-analysis, incorporating the restricted maximum likelihood method [30, 34].

Besides the overall group, we also performed stratified analyses according to menopausal status (pre and postmenopausal), body mass index-BMI $(<25$ and $\geq 25)$, estrogen receptor-ER status (ER + and ER-) of cases, and type of LAN exposure (outdoor and indoor). Furthermore, we explored the role of possible effect modifiers, by dividing the studies according to the country-specific estimated annual sunshine hours [35] into the three subgroups $(<2000,2000-3000$, and $>3000$ annual mean sunshine hours), and country solar ultraviolet B (UV-B) radiation [36].

We assessed the potential for small-study bias using funnel plots for studies reporting highest versus lowest exposure, and by performing Egger's test [37, 38] and trim-and-fill analysis [39]. We also evaluated the effect of variation across studies through the graphical overlay of study-specific predicted curves by using fixed and random effects [34]. Finally, we assessed heterogeneity by reporting $\mathrm{I}^{2}$ statistics, and by carrying out stratified analyses whenever possible such as for LAN exposure assessment method, menopausal status, participants' weight (normal vs overweight/obese), and ER status. We used Stata software (v 16.1, 2021-Stata Corp., College Station, TX), namely its 'meta' and 'drmeta' routines, for data analysis.

\section{Results}

Overall, of the 494 individual studies identified after removal of duplicates, we excluded 465 studies due to title and abstract screening, and 13 additional studies after full-text evaluation, leaving 17 studies eventually fulfilling inclusion criteria (Fig. 1). Main reasons of exclusion were the following: insufficient data, commentaries, reviews or meta-analyses, editorials, ecological studies, or lack of LAN exposure assessment (reasons reported in detail in Additional file 1: Table S3).
Table 1 presents characteristics of the 17 included studies, three with case-cohort design [40-42], six cohort [23-25, 43-45], and eight case-control [46-53]. The studies were published during 2001-2021, mainly in North America $(\mathrm{N}=10)$, followed by Europe $(\mathrm{N}=3)$, Israel $(\mathrm{N}=2)$, Australia $(\mathrm{N}=1)$, and China $(\mathrm{N}=1)$. Follow-up duration was reported in only two studies (16 and 6.1 years) [23, 42]. LAN was assessed according to two main methods: from outdoor $(\mathrm{N}=7)[23,24,40,41$, $43,44,52]$ and indoor $(\mathrm{N}=11)$ sources [41-43, 45-51, 53]. In all cohort and case-cohort studies assessing outdoor LAN, the unit of measurement for LAN was nanoWatt/square centimeters/steradian $\left(\mathrm{nW} / \mathrm{cm}^{2} / \mathrm{sr}\right)[23,24$, $40,43,44,52]$. The only exception was a Spanish study that assessed outdoor LAN using an index of outdoor blue light spectrum to calculate melatonin suppression index (MSI). MSI was estimated at each pixel of images of Madrid and Barcelona detected from the International Space Station (ISS) [41]. Indoor LAN data were evaluated based on self-reported questionnaires, for example, referring to use of lamps during the night or other sources of artificial light in the bedroom while sleeping. Additional characteristics of studies included in the systematic review are shown in the Additional file 1: Table S4.

Risk of bias assessment (Additional file 1: Table S5) showed that most studie s were at low risk of bias due to confounding, while four $\mathrm{w}$ ere at moderate risk of bias because they did not control for some breast cancer risk factors, typically family history of breast cancer, postmenopausal hormone use, or sm oking [24, 40, 47, 48]. Concerning exposure assessment, studies assessing outdoor LAN exposure were at low risk of bias [23-25, 40, $44,52]$, while those assessing both outdoor and indoor LAN or only indoor LAN were generally at moderate risk due to possible misclassification bias [41-43, 45-47, 49-51, 53]. One study was considered at high risk of bias because exposure assessment was based on a nonvalidated self-administered questionnaire [48]. All other domains were considered at low risk of bias in all studies, although four studies were judged at moderate risk of bias because some information (i.e., smoking or menopausal status) had been collected but not reported, no differences were found, or no data were presented [ 44 , $46,51]$.

Comparing the highest versus the lowest LAN exposure category, we consistently found positive associations with breast cancer risk (summary $R R=1.11$, 95\% CI 1.07-1.15). In subgroup analyses (Table 2), we found positive associations for outdoor $(R R=1.11$, 95\% CI 1.07-1.16) and indoor $(\mathrm{RR}=1.08,95 \% \mathrm{CI}$ 1.00-1.17) LAN exposure, as well as both for case-control $(\mathrm{RR}=1.11,95 \%$ CI $0.97-1.28)$ and cohort studies 


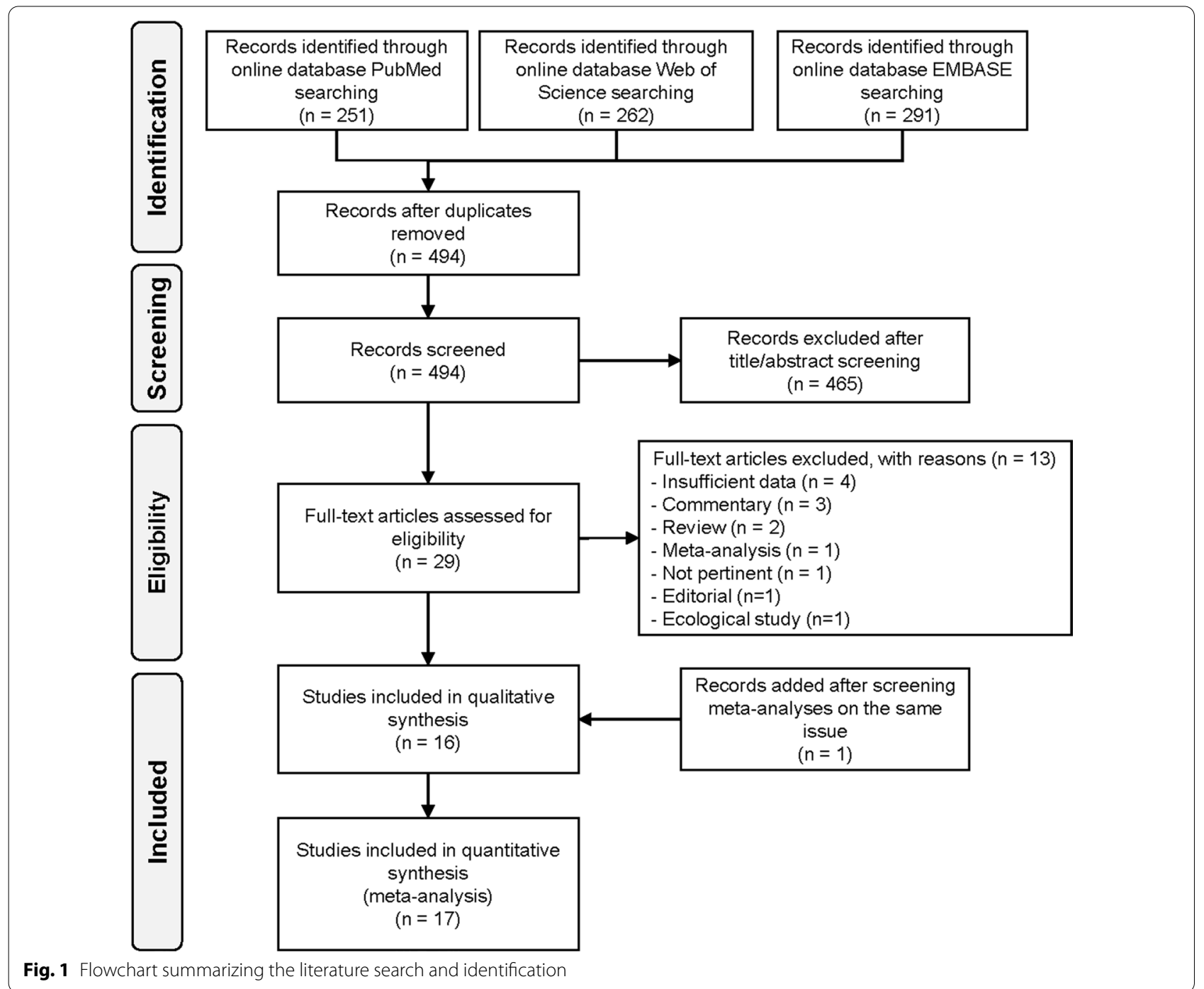

$(\mathrm{RR}=1.11,95 \% \mathrm{CI} 1.07-1.15)$ as shown in Fig. 2 and Additional file 1: Figure S1.

Eight studies assessed breast cancer risk among both pre and postmenopausal women at the moment of diagnosis, while one was restricted to postmenopausal women only. The summary RR was slightly stronger among premenopausal women $(R R=1.16,95 \% \mathrm{CI}$ 1.04-1.28) than postmenopausal women $(R R=1.07$, 95\% CI 1.02-1.13) (Fig. 3). A slight positive association among premenopausal women also emerged in the cohort/case-cohort study subgroup and for outdoor LAN exposure. Conversely, for the case-control category and indoor LAN exposure, the RR was slightly higher among postmenopausal women (Table 2 and Additional file 1: Figure S2).
In the dose-response meta-analysis, we found a positive linear relation up to $40 \mathrm{nW} / \mathrm{cm}^{2} / \mathrm{sr}$ of outdoor LAN exposure, after which a plateau was reached (Fig. 4). A substantially comparable pattern was noted for all women and in analyses stratified according to menopausal status.

Concerning possible effect-modification by ER status, few differences emerged between women with ER + and E R-b r east cancer, for whom the summary RRs were 1.09 (95\% CI 1.02-1.17) and 1.07 (95\% CI 0.92-1.23), respectively (Table 2 and Additional file 1: Figure S3). In addit ion, in the dose-response meta-analysis we found that the risk was slightly higher in the ER - subgroup compared to the ER+one. A difference also emerged above $30 \mathrm{nW} / \mathrm{cm}^{2} / \mathrm{sr}$ of outdoor LAN exposure, when the curve flattened in the ER + subgroup 


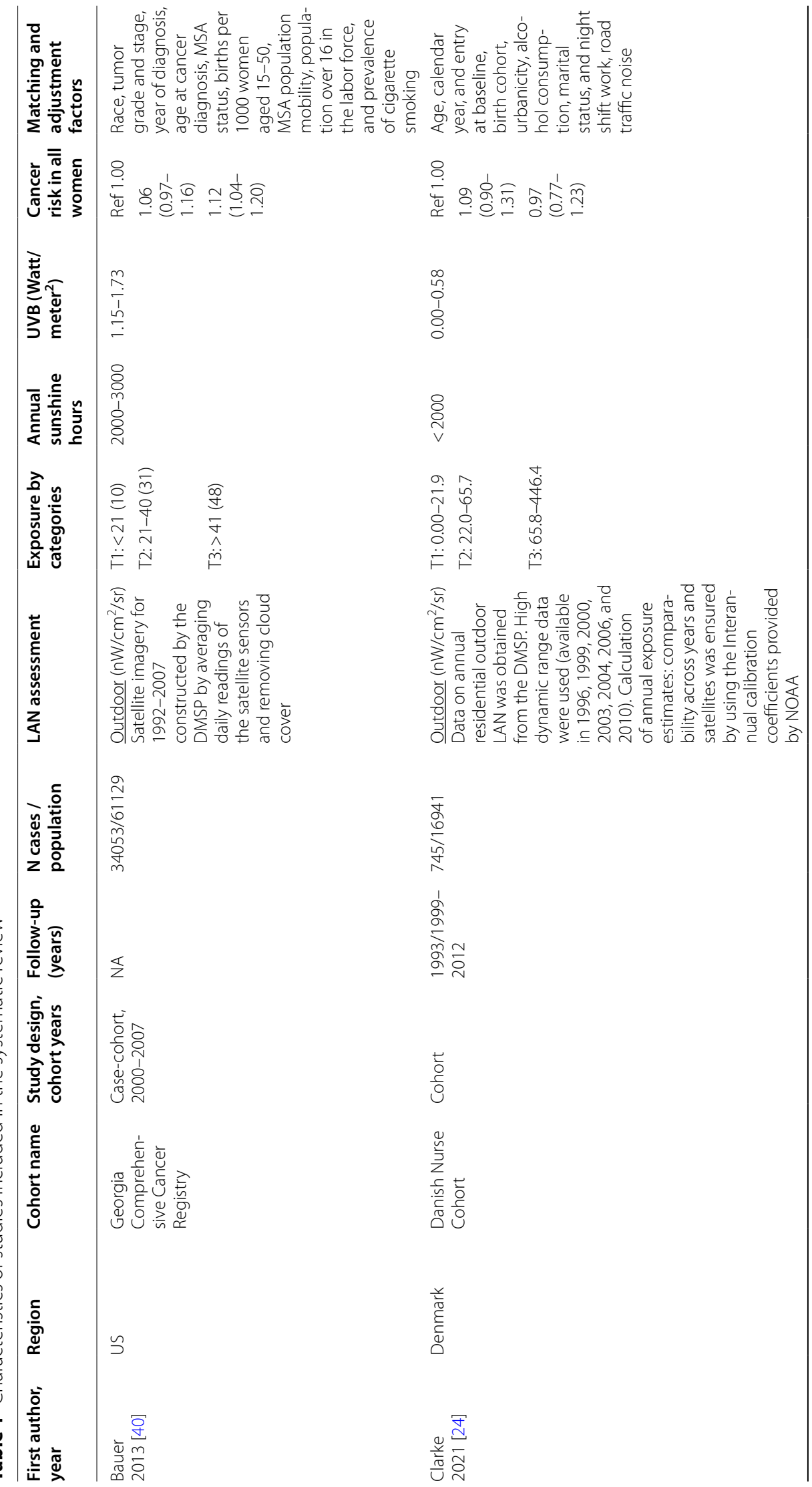




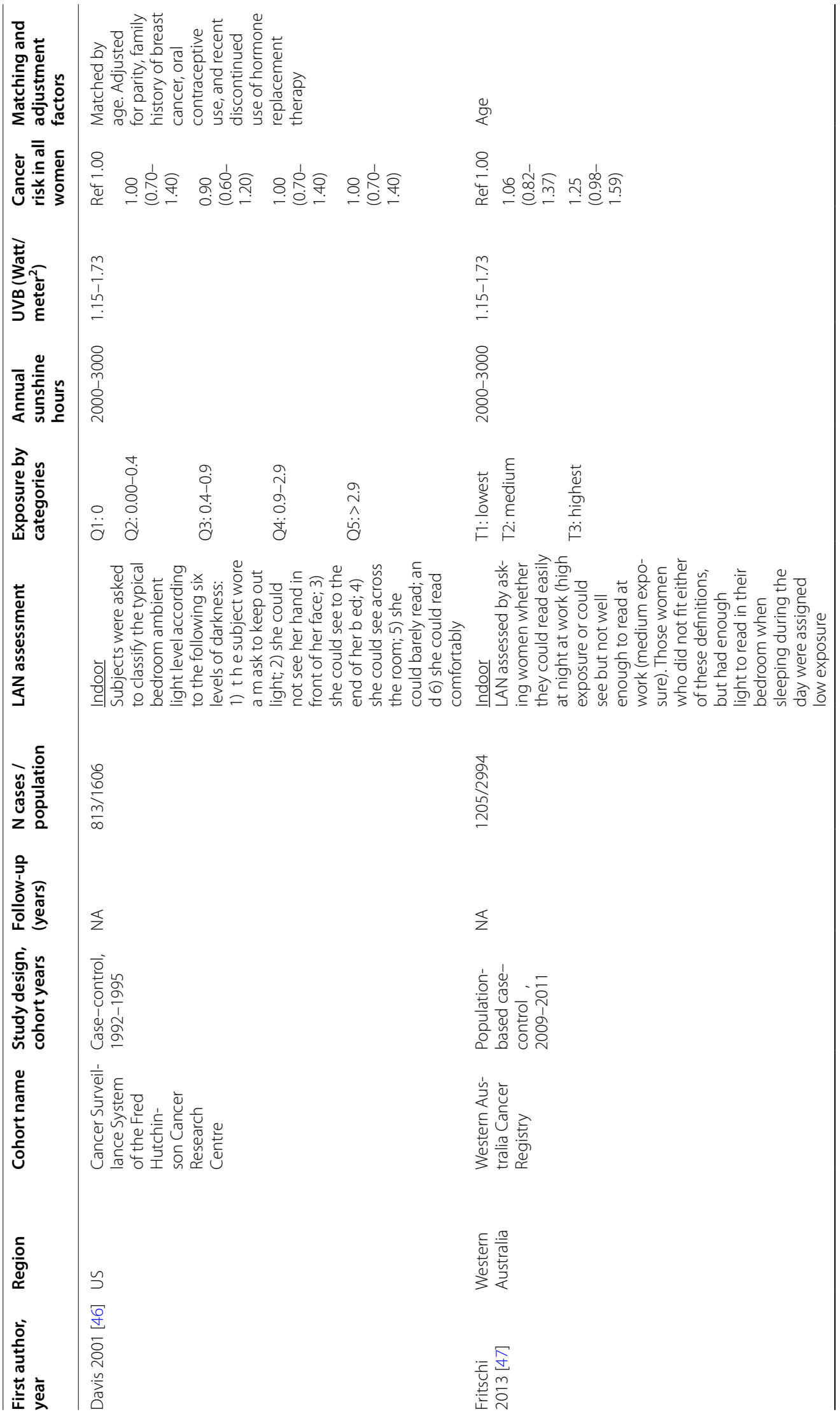




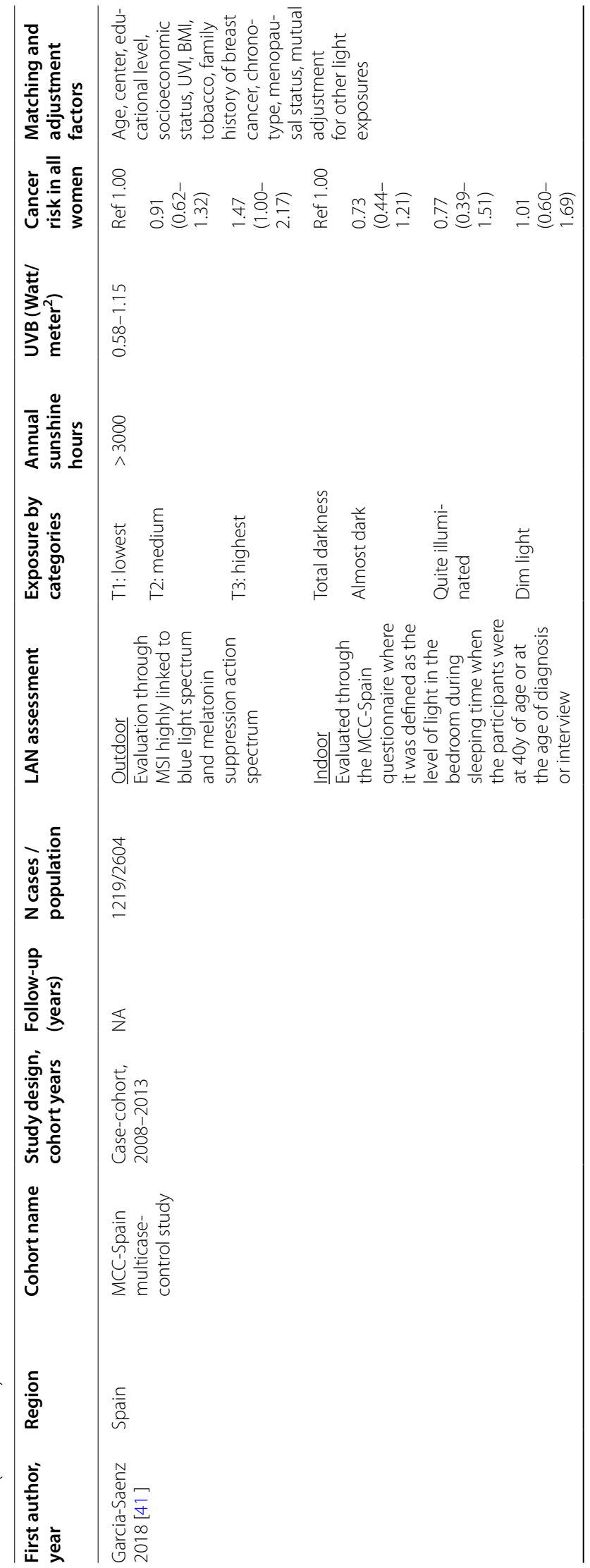




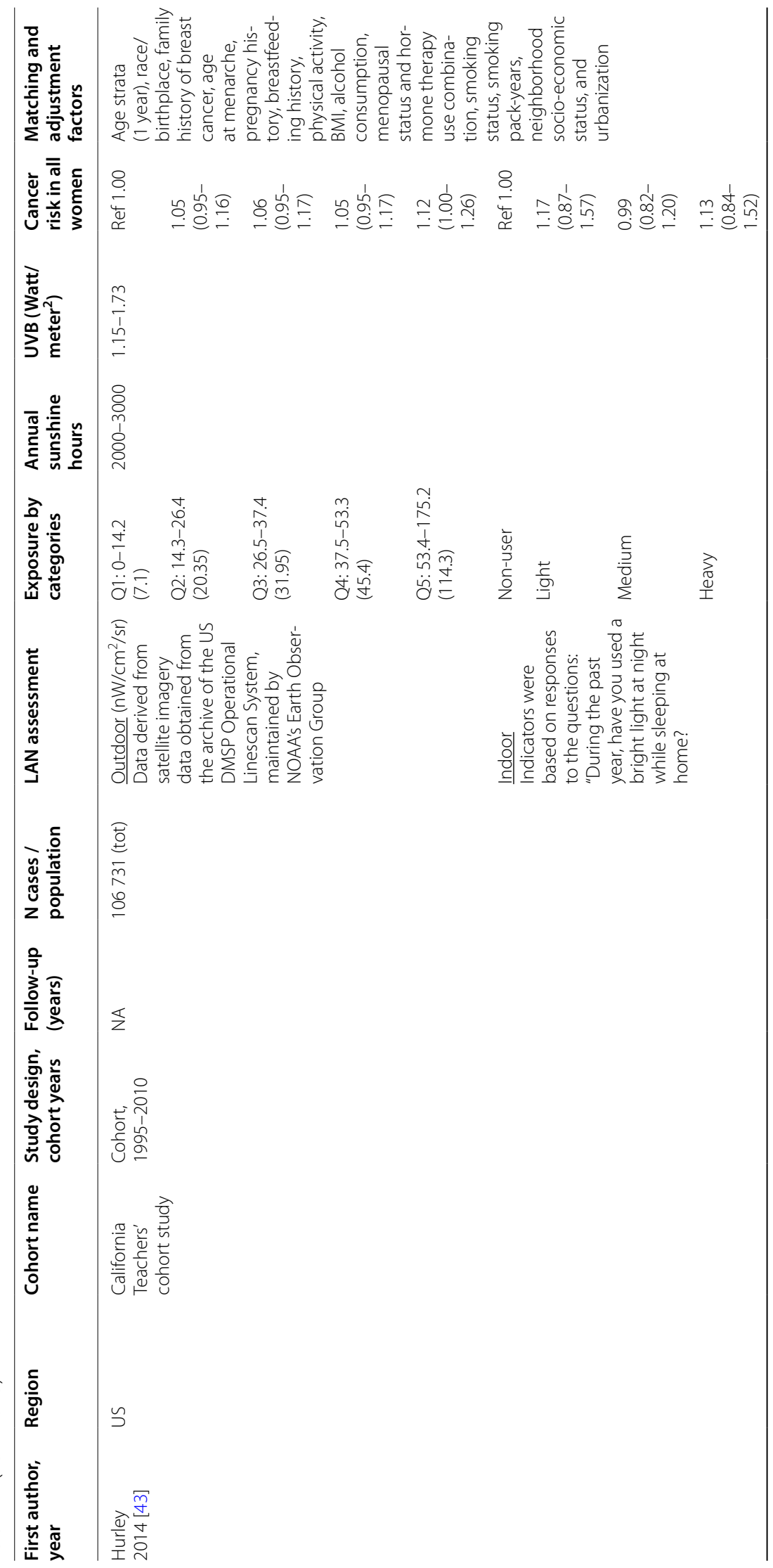




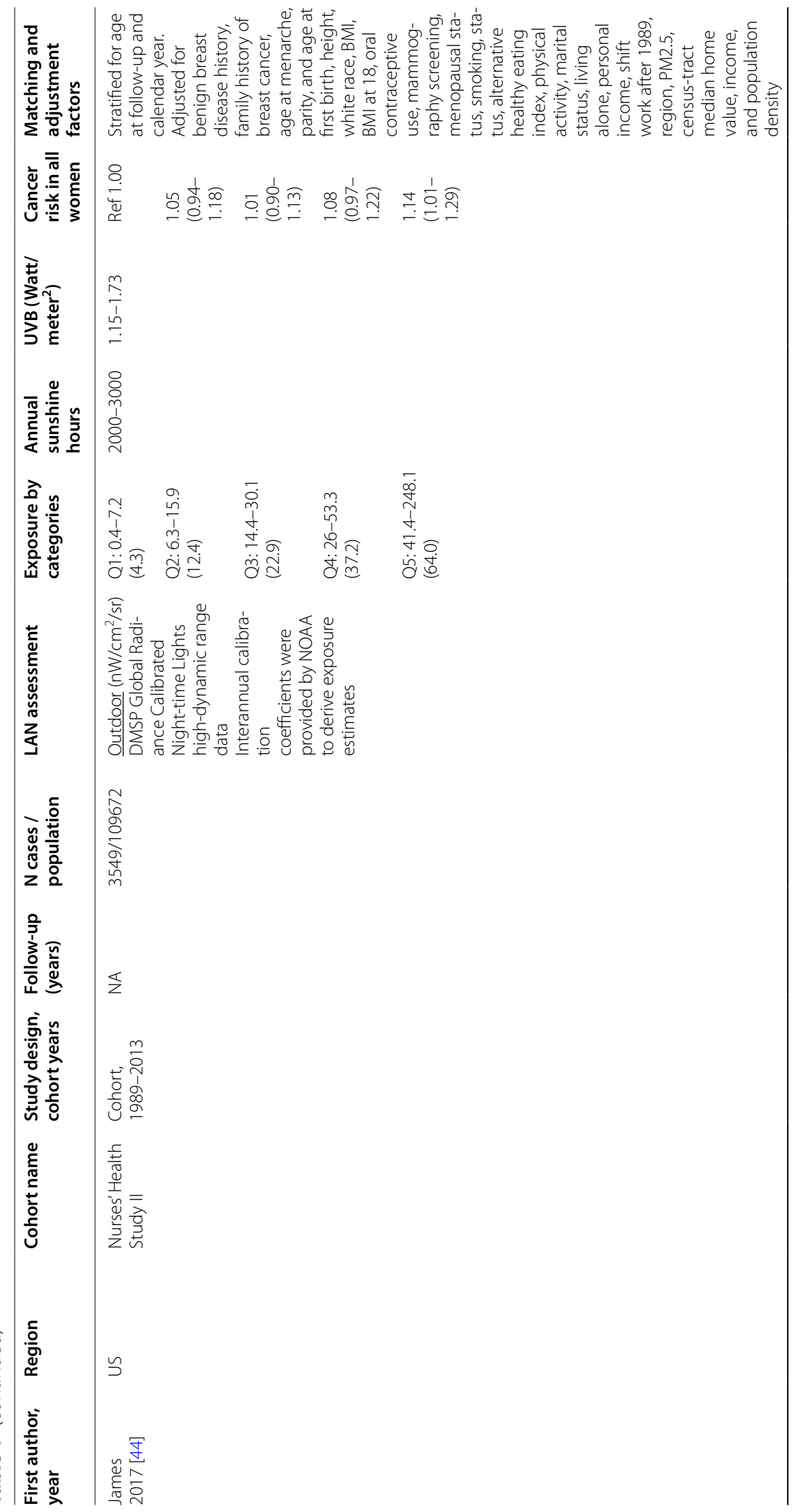




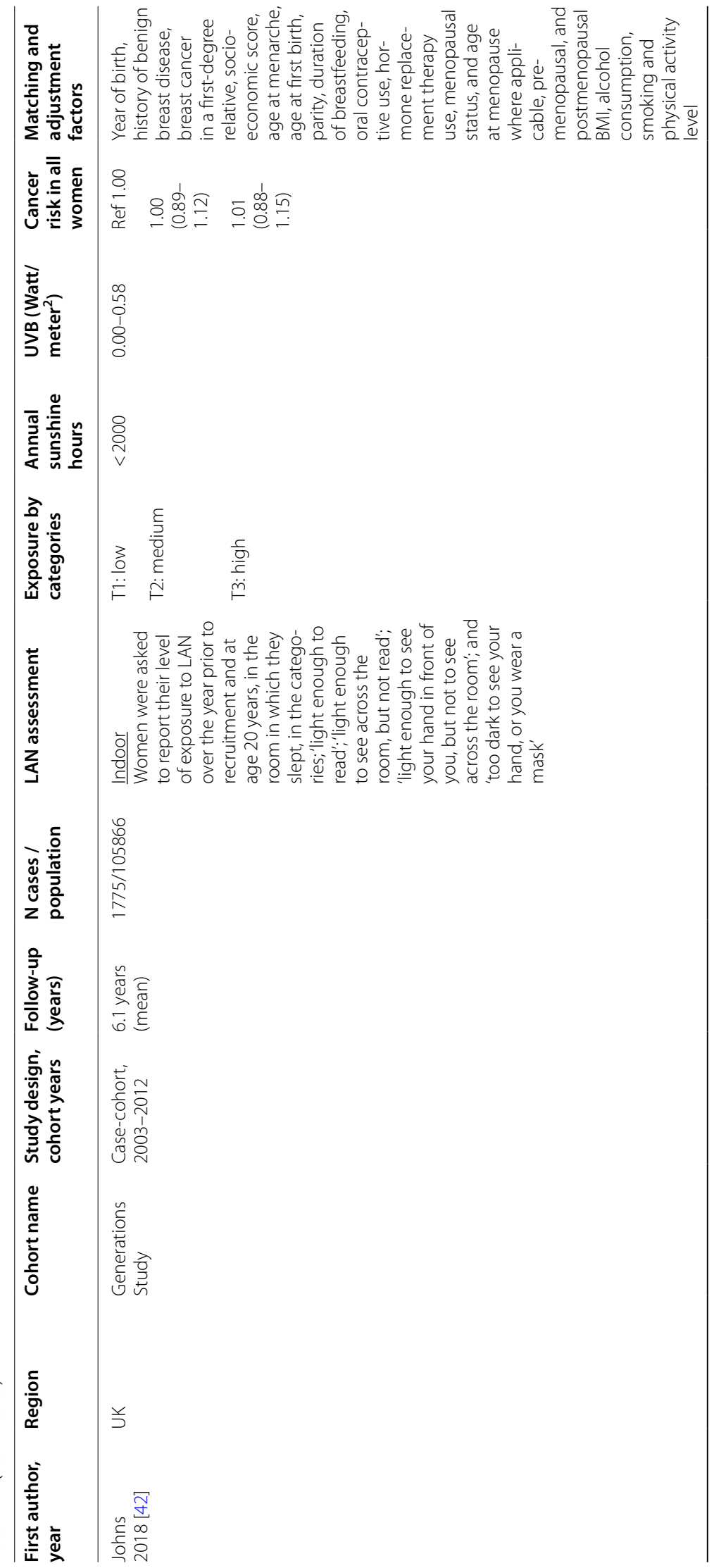




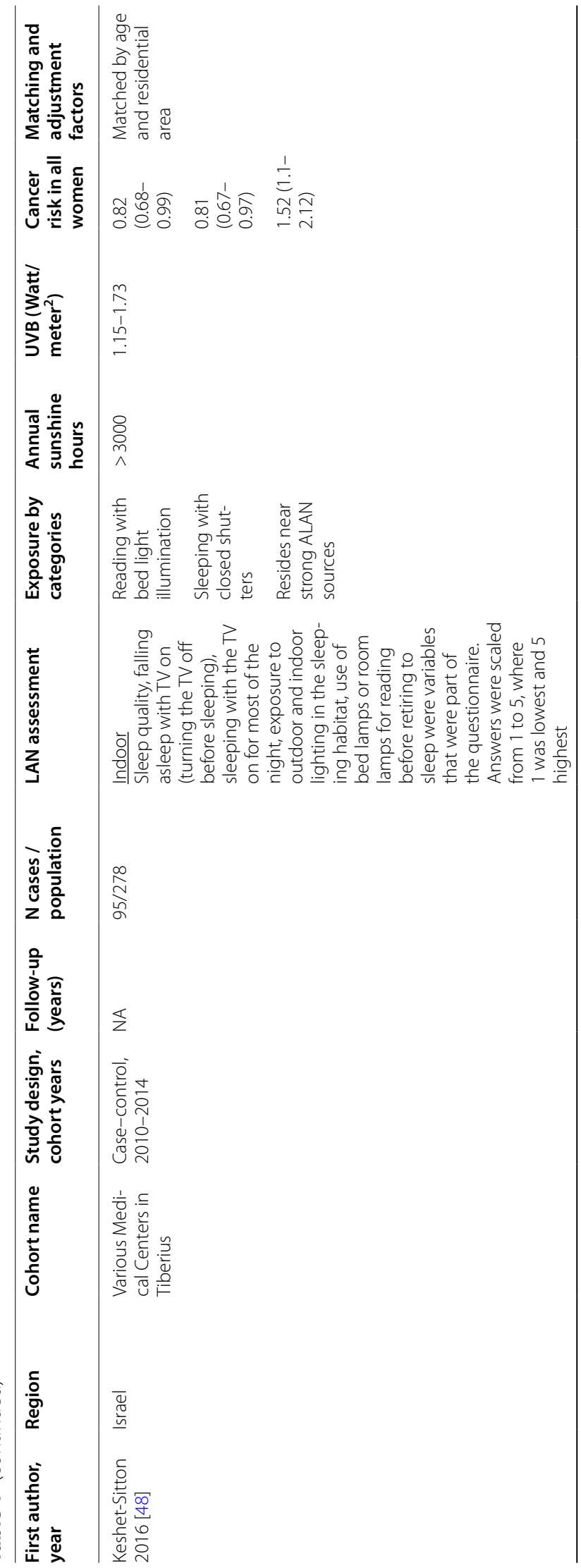




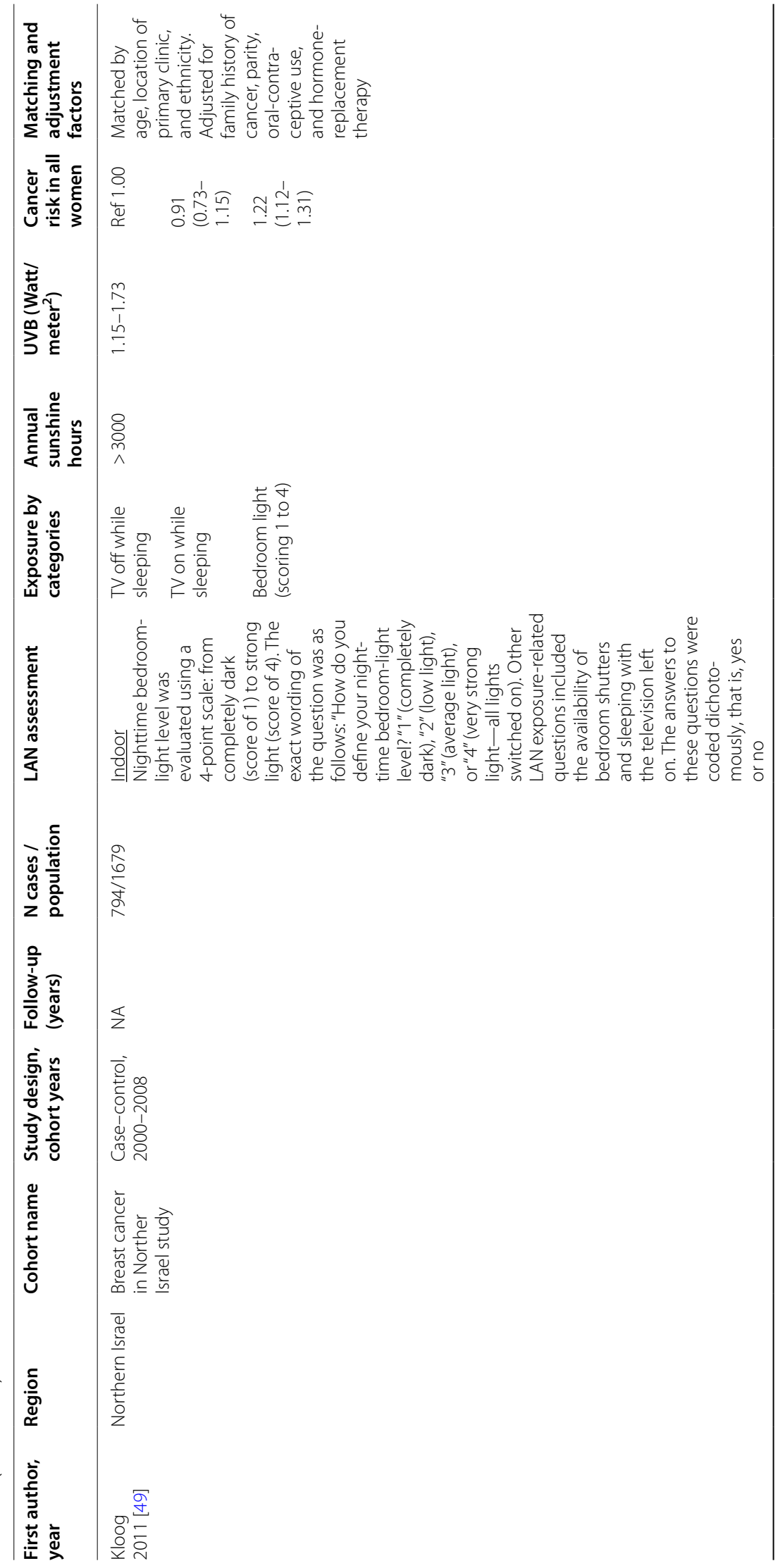




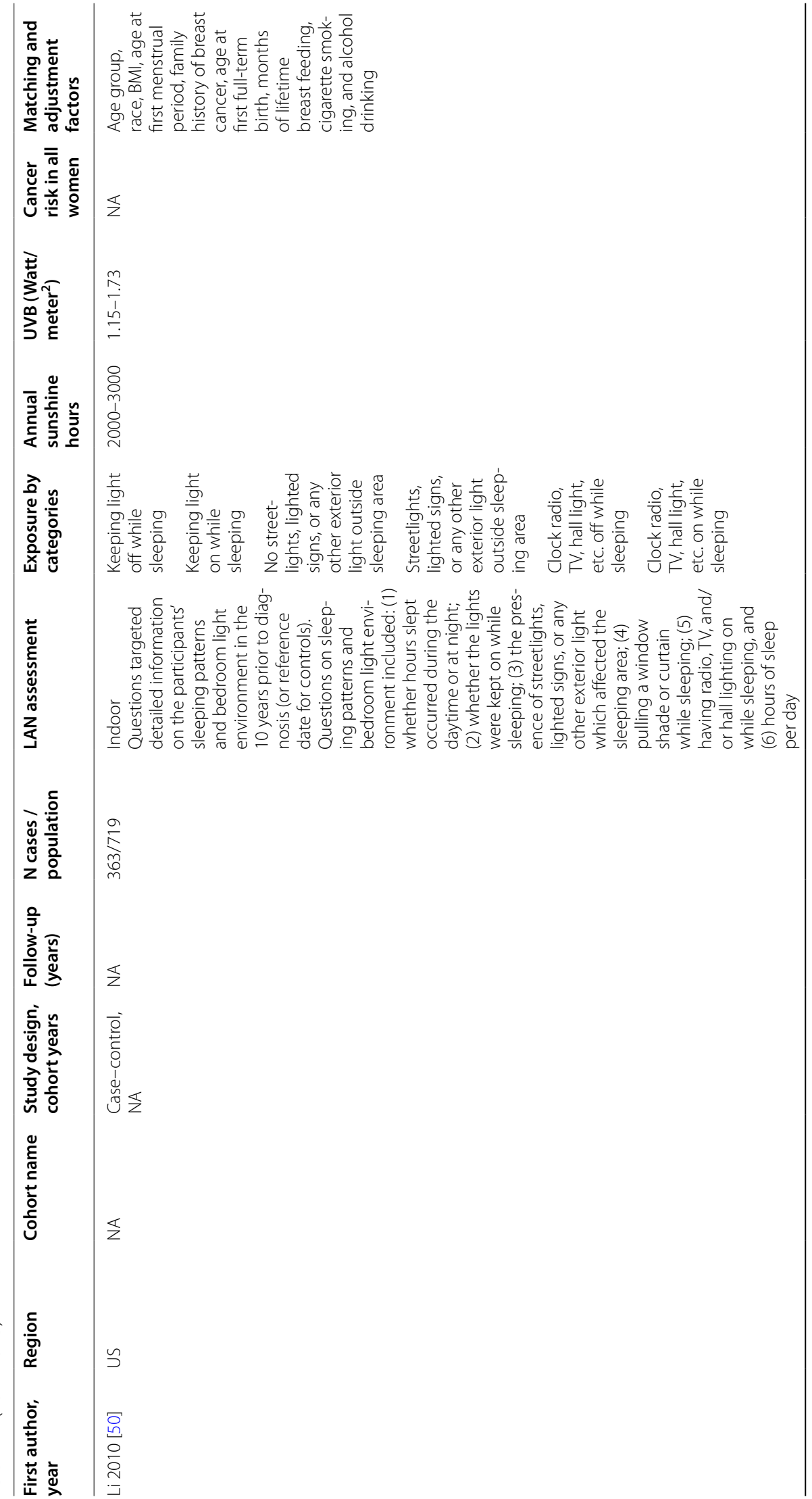




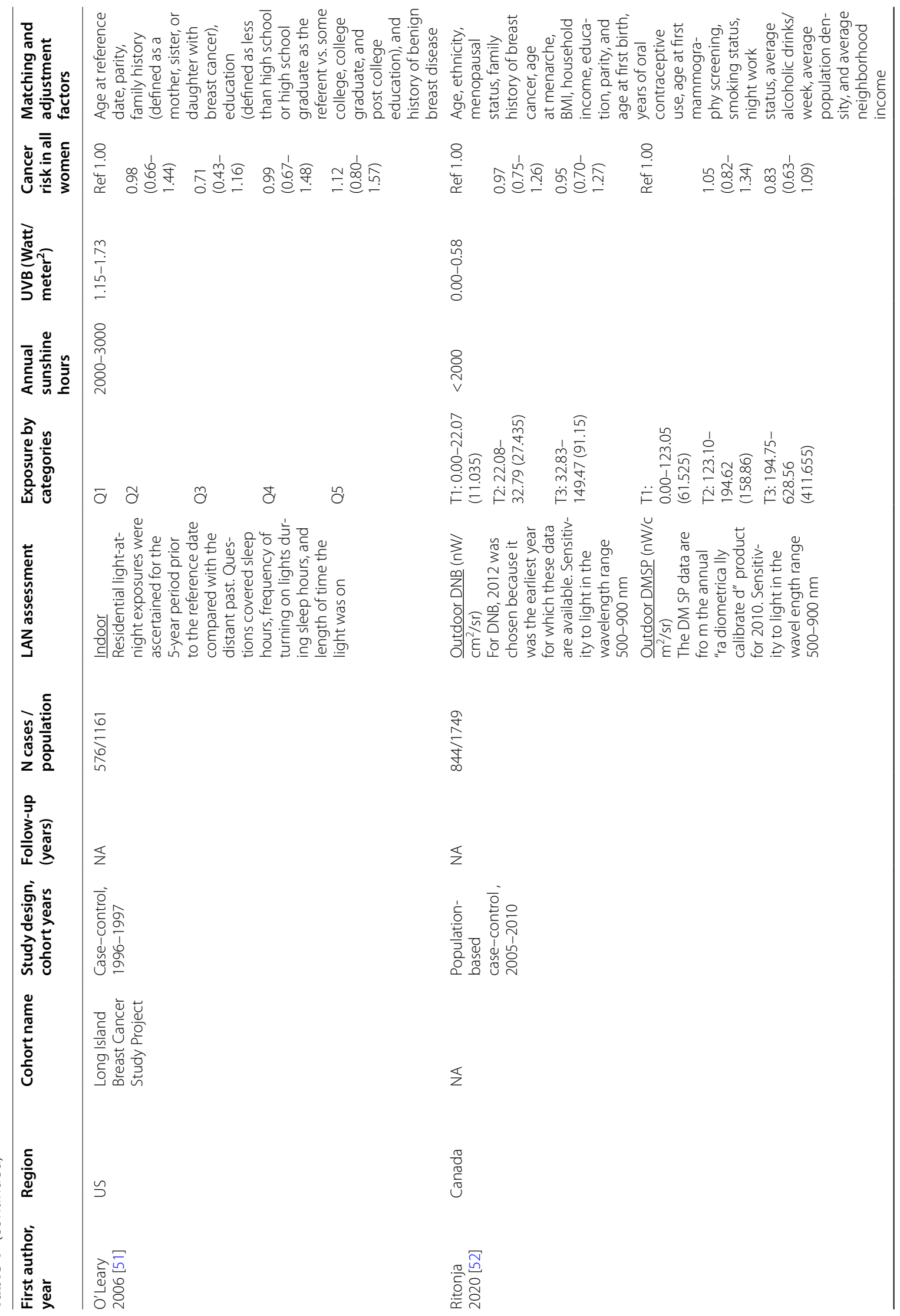




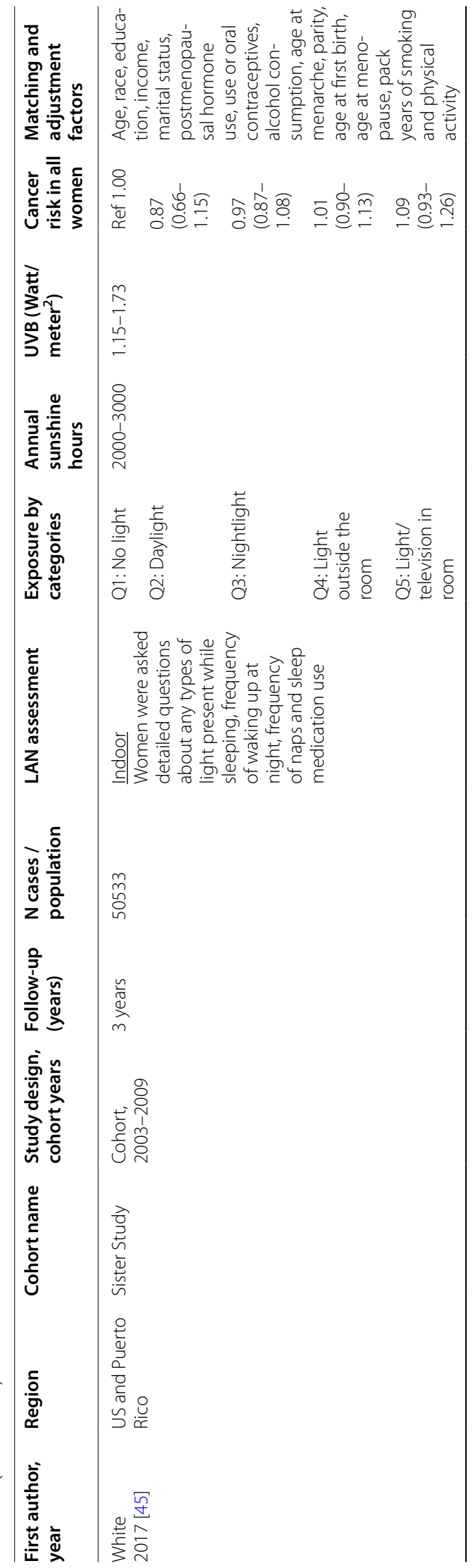




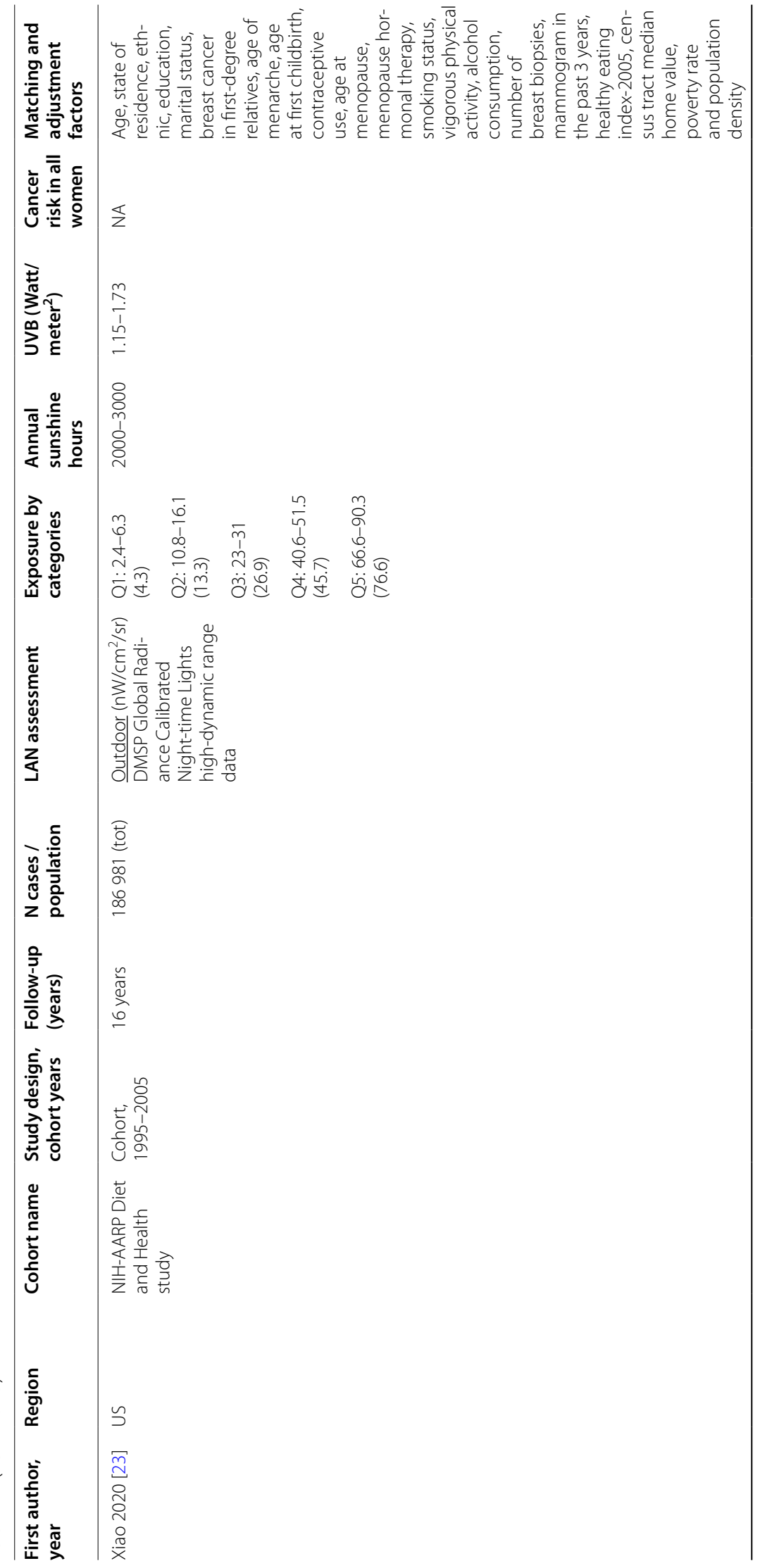




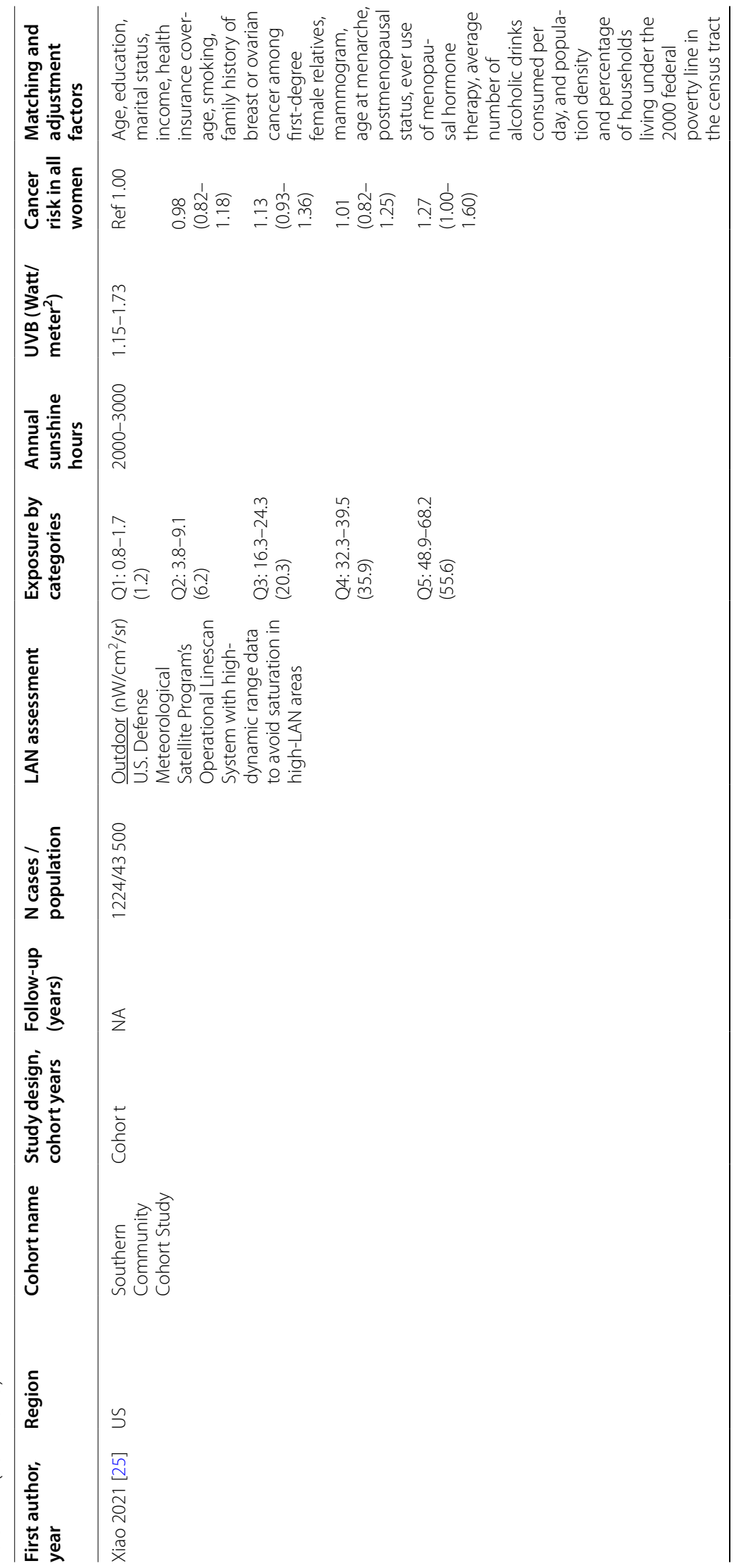




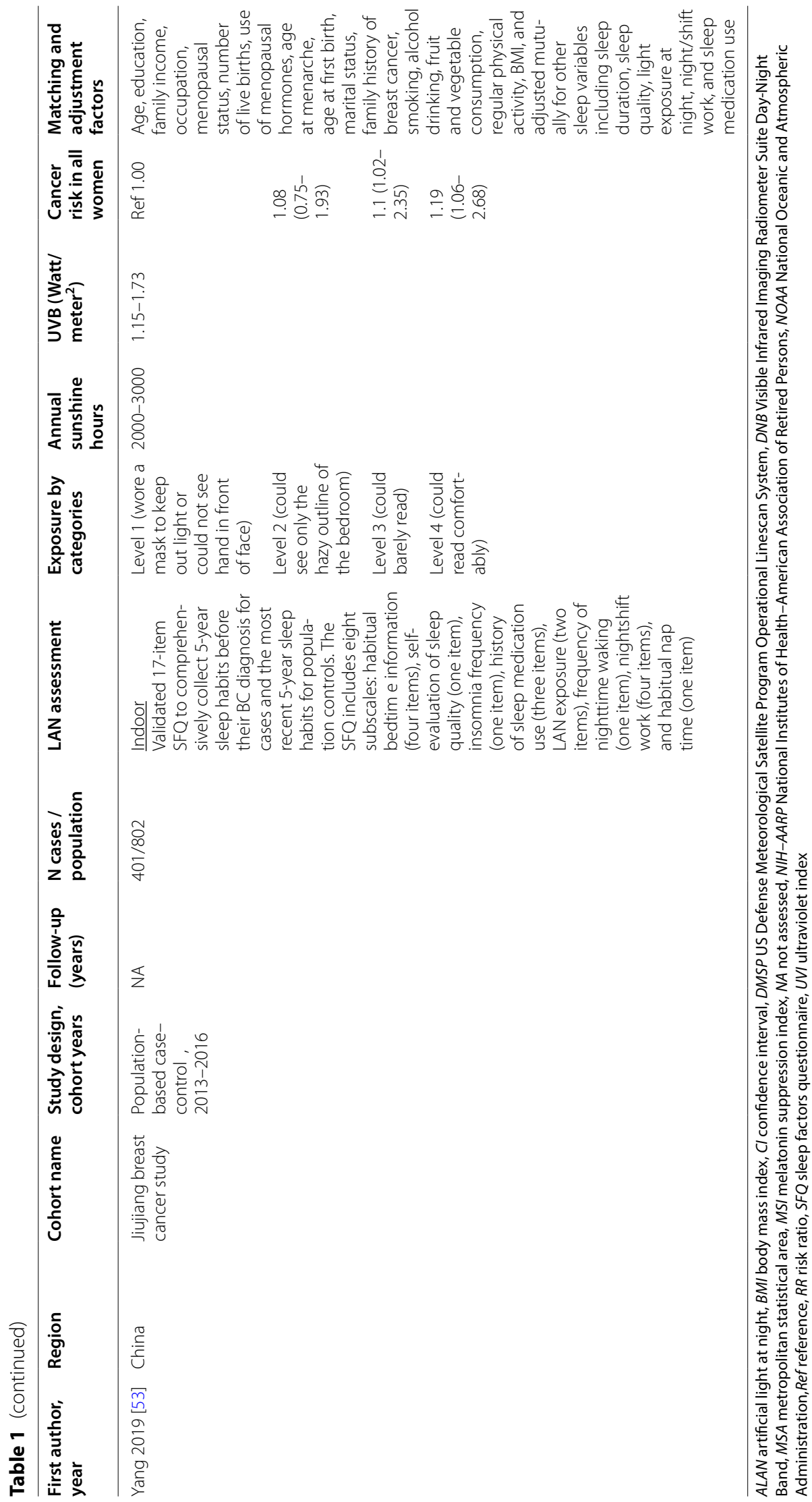


Table 2 Summary risk ratios (RRs) and 95\% confidence interval (CI) for the association between breast cancer risk and light at night exposure comparing the highest versus the lowest exposure categories for overall study population, outdoor and indoor exposure with selected subgroups

\begin{tabular}{|c|c|c|c|c|c|c|c|c|c|}
\hline \multirow[t]{2}{*}{ Breast cancer } & \multicolumn{3}{|c|}{ All studies } & \multicolumn{3}{|c|}{ Outdoor } & \multicolumn{3}{|c|}{ Indoor } \\
\hline & $n$ & $\mathrm{RR}(95 \% \mathrm{Cl})$ & $I^{2}(\%)$ & $n$ & $\mathrm{RR}(95 \% \mathrm{Cl})$ & $I^{2}(\%)$ & $n$ & $\mathrm{RR}(95 \% \mathrm{Cl})$ & $I^{2}(\%)$ \\
\hline All women & 17 & $1.11(1.07-1.15)$ & 0.0 & 7 & $1.11(1.07-1.16)$ & 0.0 & 11 & $1.08(1.00-1.17)$ & 6.5 \\
\hline \multicolumn{10}{|l|}{ Study design } \\
\hline Cohort/case-cohort studies & 9 & $1.11(1.07-1.15)$ & 0.0 & 8 & $1.11(1.07-1.16)$ & 0.0 & 4 & $1.05(0.96-1.15)$ & 0.0 \\
\hline Case-control studies & 8 & $1.11(0.97-1.28)$ & 31.5 & 1 & $0.95(0.71-1.28)$ & - & 7 & $1.14(0.98-1.34)$ & 34.2 \\
\hline \multicolumn{10}{|l|}{ Menopausal status } \\
\hline Premenopausal & 8 & $1.16(1.04-1.28)$ & 2.3 & 4 & $1.22(1.08-1.39)$ & 0.0 & 4 & $1.04(0.88-1.23)$ & 0.0 \\
\hline Postmenopausal & 9 & $1.07(1.02-1.13)$ & 0.0 & 5 & $1.07(1.00-1.14)$ & 5.9 & 4 & $1.08(0.95-1.23)$ & 4.3 \\
\hline \multicolumn{10}{|l|}{ BMl } \\
\hline$<25 \mathrm{~kg} / \mathrm{m}^{2}$ & 2 & $1.17(1.00-1.36)$ & 38.9 & 2 & $1.17(1.00-1.36)$ & 39.0 & - & - & - \\
\hline$\geq 25 \mathrm{~kg} / \mathrm{m}^{2}$ & 2 & $1.07(0.87-1.32)$ & 53.8 & 2 & $1.07(0.87-1.32)$ & 53.8 & - & - & - \\
\hline \multicolumn{10}{|l|}{ Estrogen receptor status } \\
\hline ER+ & 7 & $1.09(1.02-1.17)$ & 0.0 & 4 & $1.12(0.95-1.32)$ & 44.8 & 3 & $1.06(0.95-1.18)$ & 0.0 \\
\hline ER - & 7 & $1.07(0.92-1.23)$ & 0.0 & 4 & $1.12(0.92-1.35)$ & 0.0 & 3 & $1.01(0.81-1.25)$ & 0.0 \\
\hline \multicolumn{10}{|l|}{ LAN/sunshine hours } \\
\hline$<2000 \mathrm{~h}$ & 3 & $0.99(0.89-1.11)$ & 0.0 & 2 & $0.96(0.80-1.16)$ & 0.0 & 1 & $1.01(0.88-1.15)$ & - \\
\hline $2000-3000 \mathrm{~h}$ & 11 & $1.12(1.08-1.17)$ & 0.0 & 5 & $1.12(1.07-1.17)$ & 0.0 & 7 & $1.13(1.02-1.25)$ & 0.0 \\
\hline$>3000 \mathrm{~h}$ & 3 & $1.30(1.11-1.52)$ & 15.4 & 1 & $1.47(1.00-2.17)$ & - & 3 & $1.11(0.79-1.56)$ & 66.3 \\
\hline \multicolumn{10}{|l|}{ Equinoctial UVB } \\
\hline $0.0-0.58 \mathrm{~W} / \mathrm{m}^{2}$ & 3 & $0.97(0.87-1.08)$ & 0.0 & 2 & $0.91(0.76-1.09)$ & 0.0 & 1 & $1.01(0.88-1.15)$ & - \\
\hline $0.58-1.15 \mathrm{~W} / \mathrm{m}^{2}$ & 1 & $1.27(0.89-1.82)$ & - & 1 & $1.47(1.00-2.17)$ & - & 1 & $1.01(0.60-1.70)$ & - \\
\hline $1.15-1.73 \mathrm{~W} / \mathrm{m}^{2}$ & 13 & $1.15(1.10-1.19)$ & 5.6 & 5 & $1.12(1.07-1.17)$ & 0.0 & 9 & $1.20(1.12-1.27)$ & 0.0 \\
\hline
\end{tabular}

$B M I$ body mass index, $C l$ confidence interval, $E R$ estrogen receptor, $h$. hours, $I^{2}(\%)$ heterogeneity, LAN I ight at night, $n$ number of studies, $R R$ risk ratio, UVB ultraviolet $B$

while continued to increase in the ER - one (Additional file 1: Figure S4).

With regards to BMI status, the two studies of breast cancer risk among women with $\mathrm{BMI}<25$ or $\mathrm{BMI} \geq 25$ yielded similar positive summary RRs in both categories, though RRs were stronger in the normal-weight $(\mathrm{BMI}<25)$ group $(\mathrm{RR}=1.17,95 \% \mathrm{CI} 1.00-1.36$ and $\mathrm{RR}=1.07$, 95\% CI $0.87-1.32$, respectively (Table 2 and Additional file 1: Figure S5). A monotonic positive association emerged in the dose-response meta-analysis for the two BMI subgroups, despite the very low number of studies (Additional file 1: Figure S6).

We also performed stratified analyses according to the annual sunshine hours' map of the world (Table 2 and Additional file 1: Figure S7), dividing the 17 studies by country latitude. We divided the countries in three different groups of annual sunshine hours $(<2000 \mathrm{~h}$ : Canada, UK, Denmark; 2000-3000 h: US, Western Australia, China; $>3000$ h: Spain, Israel). Countries with annual sunshine hours $<2000$ exhibited null association $(R R=0.97$, 95\% CI 0.87-1.08). Conversely, we found a stronger association between LAN in the subgroup of countries with 2000 to 3000 annual sunshine hours $(R R=1.12$, 95\% CI
$1.08-1.17)$ as well as in countries with more than 3000 annual sunshine hours, i.e., Spain and Israel $(R R=1.30$, 95\% CI 1.11-1.52) (Additional file 1: Figure S8). These findings were also observed in analyses stratified by postmenopausal status (Additional file 1: Figure S9) and indoor/outdoor exposure, although for indoor exposure, the risk ratio was slightly higher in countries with 2000 to 3000 annual sunshine hours than those with more than 3000 (Table 2 and Additional file 1: Figure S10). Finally, when we accounted for estimated equinoctial UV-B irradiance map (Additional file 1: Figure S11) we found a null association between LAN and breast cancer risk in studies from countries with less UV-B irradiance $(R R=0.97$, 95\% CI 0.87-1.08), while an inverse association was observed in the outdoor exposure subgroup $(R R=0.91$, 95\% CI 0.76-1.09). Conversely, there was a positive association in studies from countries with higher $(>0.58 \mathrm{~W} /$ $\mathrm{m}^{2}$ ) UV-B irradiance levels (Additional file 1: Figure S12), as also confirmed when considering either outdoor or indoor exposure (Table 2).

Exclusion of the one study [48] considered at high risk of bias did not substantially alter the results (Additional file 1: Table S6). Findings were also similar when 


\begin{tabular}{|c|c|c|c|}
\hline Study & & $\begin{array}{c}\exp (\mathrm{RR}) \\
\text { with } 95 \% \mathrm{Cl}\end{array}$ & $\begin{array}{c}\text { Weight } \\
(\%)\end{array}$ \\
\hline \multicolumn{4}{|l|}{ Outdoor } \\
\hline Garcia-Saenz 2018 & $\square$ & $1.47[1.00,2.17]$ & 0.87 \\
\hline Hurley 2014 & - & $1.12[1.00,1.26]$ & 9.81 \\
\hline James 2017 & - & $1.14[1.01,1.29]$ & 8.75 \\
\hline Xiao 2020 & $\square$ & $1.10[1.02,1.18]$ & 24.67 \\
\hline Ritonja 2020 & & $0.95[0.71,1.28]$ & 1.48 \\
\hline Bauer 2013 & t & $1.12[1.04,1.20]$ & 25.57 \\
\hline Clarke 2021 & & $0.97[0.77,1.23]$ & 2.39 \\
\hline Xiao 2021 & $\longrightarrow$ & $1.27[1.00,1.61]$ & 2.37 \\
\hline Heterogeneity: $\mathrm{T}^{2}=0.00, \mathrm{I}^{2}=0.00 \%, \mathrm{H}^{2}=1.00$ & 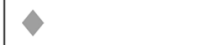 & $1.11[1.07,1.16]$ & \\
\hline \multicolumn{4}{|l|}{ Indoor } \\
\hline Garcia-Saenz 2018 & & $1.01[0.60,1.70]$ & 0.49 \\
\hline Hurley 2014 & $\rightarrow$ & $1.13[0.84,1.52]$ & 1.49 \\
\hline Davis 2001 & & $1.00[0.71,1.41]$ & 1.09 \\
\hline O' Leary 2006 & $\rightarrow$ & $1.12[0.80,1.57]$ & 1.15 \\
\hline Fritschi 2013 & - & $1.25[0.98,1.59]$ & 2.24 \\
\hline Keshet-Sitton 2016 & $\longrightarrow$ & $1.52[1.09,2.11]$ & 1.22 \\
\hline Johns 2018 & - & $1.01[0.88,1.15]$ & 7.31 \\
\hline White 2017 & - & $1.09[0.94,1.27]$ & 5.68 \\
\hline Kloog 2011 & - & $0.91[0.73,1.14]$ & 2.54 \\
\hline Yang 2019 & - & $1.19[0.75,1.89]$ & 0.61 \\
\hline Li 2010 & & $-1.40[0.71,2.75]$ & 0.29 \\
\hline \multirow[t]{2}{*}{ Heterogeneity: $\mathrm{T}^{2}=0.00, \mathrm{I}^{2}=6.51 \%, \mathrm{H}^{2}=1.07$} & 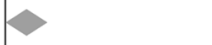 & $1.08[1.00,1.17]$ & \\
\hline & 2 & & \\
\hline
\end{tabular}

Random-effects REML model

Fig. 2 Risk ratio (RR) with 95\% confidence interval (Cl) for the association between light at night exposure and $r$ isk o f breast cancer ( $N=17$ studies) com paring the highest versus the lowest exposure category in studies assessing outdoor and indoor exposure. The squares represent point estimates of RR and horizontal lines represent their $95 \%$ confidence intervals (Cls). The area of each square is proportional to the inverse of the variance of the estimated log RR. The diamonds represent the combined RR for each subgroup and the overall RR for all studies. The solid line represents $R R=1$

we additionally excluded the two studies considered at moderate risk of bias in selection of reported results $[46,51]$ (Additional file 1: Table S7). To further limit the effect of potential biases, we then performed the analyses excluding three additional studies [24 40,47] considered at moderate risk of bias due to confounding. Still, there were little changes in the results, and the estimates were substantially confirmed (Additional file 1: Table S8). Similarly, analysis of conditional study-specific lines arising from the estimated random-effects model yielded homogeneous results overall and among premenopausal women, while among postmenopausal women, slightly higher variation was noted (Additional file 1: Figure
S13). Finally, evaluation of small-study bias suggested no occurrence of bias due to symmetric distribution and no studies were added when running trim-an-fill analysis both in overall studies (Additional file 1: Figure S14) and in analyses stratified by menopausal status (Additional file 1: Figure S15) and exposure assessment (Additional file 1: Figure S16).

\section{Discussion}

Higher urbanization has prompted substantial changes in peoples' lifestyles as compared with our ancestors. Nowadays, over $80 \%$ of the World's population and close to $100 \%$ of the people in the United States and 


\begin{tabular}{|c|c|c|c|c|}
\hline Study & & & $\begin{array}{c}\exp (\mathrm{RR}) \\
\text { with } 95 \% \mathrm{Cl}\end{array}$ & $\begin{array}{l}\text { Weight } \\
(\%)\end{array}$ \\
\hline \multicolumn{5}{|l|}{ Premenopausal } \\
\hline Garcia-Saenz 2018 & & & $1.09[0.57,2.09]$ & 0.54 \\
\hline Hurley 2014 & & $\longrightarrow$ & $1.34[1.07,1.68]$ & 4.32 \\
\hline James 2017 & & $\rightarrow-$ & $1.20[1.02,1.41]$ & 8.62 \\
\hline Ritonja 2020 & & & $1.06[0.68,1.66]$ & 1.12 \\
\hline Fritschi 2013 & & & $1.10[0.78,1.55]$ & 1.92 \\
\hline Johns 2018 & & 一 & $1.00[0.81,1.24]$ & 4.98 \\
\hline Yang 2019 & & & $1.16[0.69,1.95]$ & 0.84 \\
\hline Li 2010 & & & $1.10[0.37,3.30]$ & 0.19 \\
\hline Heterogeneity: $\tau^{2}=0.00, I^{2}=2.29 \%, H^{2}=1.02$ & & $>$ & $1.16[1.04,1.28]$ & \\
\hline \multicolumn{5}{|l|}{ Postmenopausal } \\
\hline Garcia-Saenz 2018 & & & $1.31[0.84,2.04]$ & 1.16 \\
\hline Hurley 2014 & & - & $1.04[0.90,1.20]$ & 10.92 \\
\hline James 2017 & & - & $0.95[0.78,1.15]$ & 5.99 \\
\hline Xiao 2020 & & & $1.10[1.02,1.18]$ & 42.54 \\
\hline Ritonja 2020 & & - & $0.90[0.64,1.27]$ & 1.92 \\
\hline Fritschi 2013 & & $\rightarrow$ & $1.17[0.94,1.45]$ & 4.81 \\
\hline Johns 2018 & & • & $1.00[0.85,1.18]$ & 8.40 \\
\hline Yang 2019 & & & $1.14[0.74,1.74]$ & 1.25 \\
\hline Li 2010 & & & $1.40[0.71,2.75]$ & 0.50 \\
\hline \multirow[t]{2}{*}{ Heterogeneity: $\tau^{2}=0.00, I^{2}=0.00 \%, H^{2}=1.00$} & & $\bullet$ & $1.07[1.02,1.13]$ & \\
\hline & $1 / 2$ & 2 & & \\
\hline
\end{tabular}

Random-effects REML model

Fig. 3 Risk ratio (RR) with 95\% confidence interval (Cl) for the association between light at night exposure and risk of breast cancer ( $N=9$ studies) among premenopausal and postmenopausal women, comparing the highest versus the lowest exposure category. The area of each grey square is proportional to the inverse of the variance of the estimated log RR. Black diamonds represent point estimates of RR and horizontal lines represent their $95 \%$ confidence intervals (Cls). The open diamonds represent the combined RR for each subgroup and the overall RR for all studies. The solid line represents $R R=1$

Europe live under skies polluted by light [54], one of the key environmental factors characterizing the Western world environment . Besides residence-related artificial light (i.e., urban light pollution), other sources of nonnatural LAN are electronic devices (TVs, smartphones, tablets, computers, etc.) or lights turned on during night at home or at the workplace. The possible carcinogenic effects of LAN has been recently assessed also by the U.S. National Toxicology Program (NTP) cancer hazard assessment [55]. NTP concluded that there was moderate evidence for a causal relation between LAN exposure and human cancer, since LAN may act through different mechanisms of circadian disruption and its biological effects are the same of well-known recognized carcinogens [55].
Over the last twenty years, the association between LAN exposure and breast cancer risk has been assessed primarily in occupational settings, specifically among night-shift workers [56-60]. These studies generally found a slight to substantial excess for breast cancer in women working graveyard shifts. Most recently, epidemiological studies investigating LAN exposure, in most cases independently from nightshift work, and its association with risk of breast cancer in the general population have greatly increased. In longitudinal studies, metrics of outdoor LAN have been collected through sophisticated methods such as the US DMSP Operational Line-Scan System or the Visible Infrared Imaging Radiometer Suite $\mathrm{DNB}$, and expressed as $\mathrm{nW} / \mathrm{cm}^{2} / \mathrm{sr}$, except for one study [41], which was based on a visual artificial light-at-night 


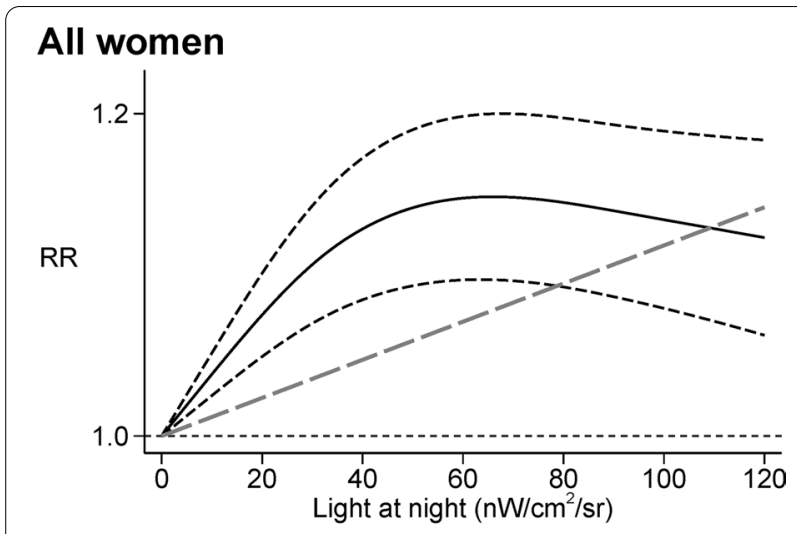

Premenopausal

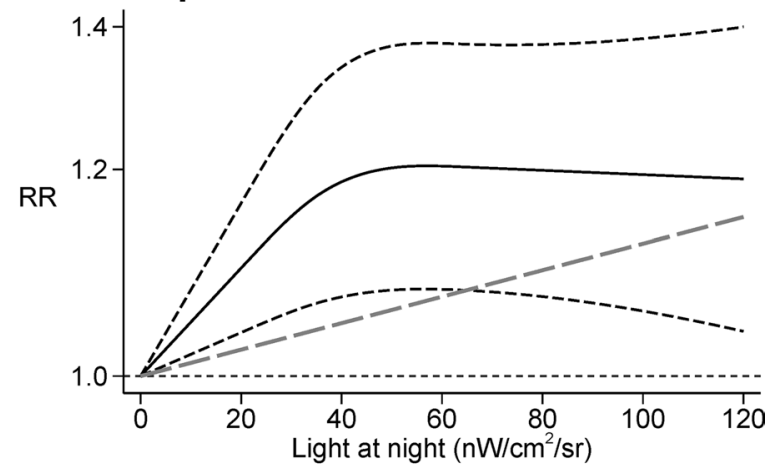

Postmenopausal

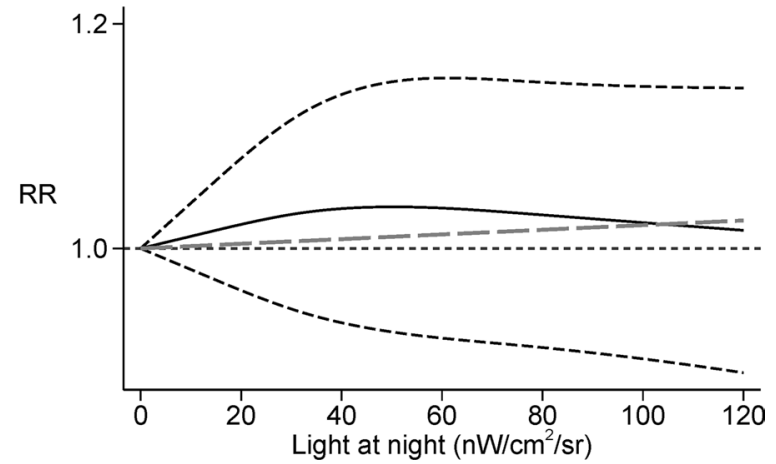

Fig. 4 Dose-response meta-analysis between light at night and risk of breast cancer among all women [23-25, 40, 43, 44, 52] and between light at night and risk of breast cancer in premenopausal $[43,44,52]$ and postmenopausal women $[23,43,44,52]$. Spline curve (black solid line) with 95\% confidence limits (black dashed lines), and linear trend estimation (long-dashed gray line). $R R$ risk ratio

(ALAN) assessment to estimate ground-based spectrum of the light emission, and melatonin suppression index for outdoor blue light spectrum. A Canadian study used both DNB and DMSP data. Even if DNB has a higher resolution and a calibrated radiometer, DMSP was used in our analysis for comparison with other studies [52].

Most case-control studies, in turn, have assessed LAN exposure using self-administered questionnaires regarding sleep and/or night habits. Exposure assessment in these studies has included frequency of waking up and turning on lights during night, sleeping with the TV on or off, darkness level in the room, residency near strong artificial LAN sources, wearing a mask while sleeping, keeping lights on or off while sleeping.

There is some biological plausibility for a LAN breast cancer association, given the observation that repeated exposure to artificial light during night hours might induce DNA damage and oxidative stress, alter melatonin and estrogen synthesis and metabolism, inflammation and immune function, and disrupt metabolic function [18]. More specifically, three mechanisms have been proposed to explain the link between LAN and some types of cancers. LAN could inhibit melatonin secretion directly [61], through sleep deprivation (also affecting cell proliferation and cytokines production [62]), and through chronodisruption [63, 64]. Along these lines, previous studies referred more generally to night shift work than to LAN exposure, but night shift work is a far more complex exposure, including among other changes in sleep habits, sleep deprivation, eating during the night [61]. For this reason, we focused our attention more specifically on exposure to LAN as a factor associated with higher incidence of breast cancer, rather than night shift work, though the latter may confound to some extent the association between LAN and breast cancer risk.

We found a consistent positive association between LAN and breast cancer risk overall and among several subgroups, including premenopausal women, those with $\mathrm{BMI}<25$, and those living in countries experiencing more than 3000 sunshine hours a year. The risk of developing breast cancer was almost monotonically associated with outdoor LAN up to the value of $40 \mathrm{nW} / \mathrm{cm}^{2} /$ sr, above which the threshold of the curve flattened. The association was stronger among premenopausal women, suggesting that younger women or women with higher endogenous levels of estrogens may have greater susceptibility to the effects of LAN. Effect measure modification by menopausal status could be due to different underlying biological mechanisms. Previous studies have reported that the suppressive effect of LAN on melatonin secretion may be stronger among younger people, tending to decrease with age $[62,65]$. In addition, LAN may impact on the length of the menstrual cycle through endocrine-disrupting properties, thus leading to higher breast cancer risk in the premenopausal period [66].

With regard to confounding factors, solar UV-B radiation is thought to be protective for breast cancer development. The inverse association between cancer risk and UV-B radiation was hypothesized for the first time by the Garland brothers in 1980 [67] who theorized sunlightinduced increases in vitamin $\mathrm{D}_{3}$ may confer protection. 
The final product of the vitamin $\mathrm{D}_{3}$ metabolism is the calcitriol, which has many anti-carcinogenic properties including inhibiting cellular proliferation [68]. Across the years, many studies have investigated the potential protective role of the UV-B radiation against different types of cancer [69-72]. A remaining question is the relationship between LAN and ultraviolet radiation. We found a positive association between LAN and breast cancer risk in countries exposed to higher levels of UV-B radiation $\left(>0.58 \mathrm{~W} / \mathrm{m}^{2}\right)$. Conversely, there was no association between LAN and breast cancer risk in countries with low UV-B irradiance $\left(<0.58 \mathrm{~W} / \mathrm{m}^{2}\right)$.

We considered another confounding factor that also correlates with UV-B radiation and could influence the outcome risk: the influence of annual sunshine hours [73, 74]. We found an increased breast cancer risk associated with LAN in countries where annual sunshine exposure exceeded $3000 \mathrm{~h}$. A positive association was also found in countries where sunshine ranged 2000-3000 h/years, while no appreciable association was observed in countries where there were fewer sunshine hours. This could be explained by different habits of people living in different countries, which may reflect epigenetics adaptation [75]. As indicated by a 2014 Italian study, humans' biological clocks may have adapted to different environmental conditions during migrations, consistent with studies on insects [76], birds [77], and fish [78] living at different latitudes. These studies analyzed, in particular, the evolution of circadian genes which may be related to selective pressure exerted from latitude, temperature, ultraviolet radiation flux [79]. Consequently, people living in countries exposed to less than 2000 annual sunshine hours are less susceptible to higher frequency of light during night compared to people living in countries exposed to more annual sunshine hours. An explanation may be the presence of different alleles of their circadian genes, which acted to adapt the organism to different living conditions such as different latitudes. [80]. Finally, we may hypothesize that if people residing in "darkest countries" have artificial light kept on also during the daytime, they may not be as strongly influenced by higher levels of LAN because of different environment-adaptive alleles which acted to adapt the organism to light regimes diverse from the natural ones, as has been shown in animals [81]. In the meantime, another hypothesis that may explain the stronger association in relation to the annual sunshine hours is represented by the cumulative effect of longer daily sunshine hours with LAN exposure. In fact, those living in "brightest countries" are exposed to higher levels of light, which may lead to greater melatonin suppression levels and chronodisruption. Hence, the combination of daily sunshine hours and LAN may increase breast cancer risk.
Our results are relatively consistent with two previous meta-analyses [21, 22], with the exception of the subgroup analysis according to menopausal status, where our results were similar to those of Lai et al. [21] but conflicted with those of Wu et al. [22]. However, to our knowledge this meta-analysis is the first to have assessed the dose-response between LAN and breast cancer risk, particularly among premenopausal women. In addition, owing to three new, recently-published studies we could include in the present review, we could re-assess the LAN-breast cancer relation according to ER cancer type, also performing a dose-response meta-analysis in these subgroups. Though our findings support a harmful effect of LAN in both the ER + and ER - breast cancer subtypes, at high exposure levels i.e., above $30 \mathrm{nW} / \mathrm{cm}^{2} / \mathrm{sr}$ the curve flattened in women with ER + disease but still increased in the ER - subgroup.

Our review has some strengths and limitations. Firstly, we used a newly developed meta-analytic tool for exploring the full shape of the dose-response, enabling us to assess the shape of the relation between LAN exposure and breast cancer risk over a wide range of exposure and across population subgroups. Our approach also yielded some indications of the threshold exposure levels that can increase breast cancer risk. Moreover, we systematically used the most adjusted model from each included study, thereby accounting for major confounders of the association.

Nonetheless, we acknowledge that some summary estimates are still statistically unstable due to the low number of studies still characterizing some subgroups. In addition, we could not rule out that unmeasured confounding was still likely in the investigated studies, and therefore influenced the findings. An example of such potential identified confounder could be the possibility that air pollution is heavier in urban areas, where the highest levels of LAN exposure are also detectable. In particular, LAN exposure may correlate with higher levels of traffic-related pollutants, including noise, as indicated by its inverse correlation with greenness and green space diversity [82, 83]. Unfortunately, only one study included traffic noise in the multivariable model, thus hampering the evaluation of any independent effects of this factor and its potential for confounding in LANrelated studies. Additionally, other confounders may be those related to the occupational night environment, especially for studies assessing LAN exposure among nightshift workers [55]. Another limitation could be the limited capacity of outdoor LAN to adequately reflect personal light exposure due to differences in indoor lightning, use of electronic devices, nighttime activities, or window treatments, being these only some of the potential other sources of exposure [83, 84]. Therefore, 
future studies should ideally use validated questionnaires combined with satellite data to more accurately measure individual LAN exposure. Finally, funnel plots and trimand-fill analysis suggest a negligible probability of smallstudy effects in overall and stratified analyses.

\section{Conclusions}

Our review suggests a positive association between LAN exposure and risk of breast cancer, particularly in some subgroups, especially in premenopausal women, while few differences substantially emerged according to ER status, thus ongoing efforts to minimize LAN exposure might contribute to decrease human burden of diseases [85-87].

\begin{abstract}
Abbreviations
ALAN: Artificial Light At Night; BMI: Body Mass Index; Cl: Confidence Interval; ER: Estrogen Receptor; DMSP: US Defense Meteorological Satellite Program Operational Linescan System; DNB: Visible Infrared Imaging Radiometer Suite Day-Night Band; I²: Heterogeneity; LAN: Light At Night; RR: Risk Ratio; UV-B: Ultraviolet B.
\end{abstract}

\section{Supplementary Information}

The online version contains supplementary material available at https://doi. org/10.1186/s12942-021-00297-7.

\section{Acknowledgements}

Not applicable.

\section{Authors' contributions}

TU and TF designed the original study, and with MV and LAW analysed and interpreted the data and drafted the article. All authors read and approved the final manuscript.

\section{Funding}

This work was supported by a grant "Dipartimenti di Eccellenza 2018 - 2022, MIUR, Italy" to the Department of Biomedical, Metabolic and Neural Sciences (Drs. Filippini, Urbano and Vinceti) and by a grant FAR IMPULSO2020 no. 494/2020 (Dr. Filippini).

\section{Availability of data and materials}

All data generated or analyzed during this study are included in this published article and its additional information files.

\section{Declarations}

Ethics approval and consent to participate

Not applicable.

\section{Consent for publication}

Not applicable.

\section{Competing interests}

The authors declare that they have no competing interest.

\section{Author details}

${ }^{1}$ CREAGEN - Environmental, Genetic and Nutritional Epidemiology Research Center, Department of Biomedical, Metabolic and Neural Sciences, University of Modena and Reggio Emilia, Modena, Italy. ${ }^{2}$ Department of Epidemiology, Boston University School of Public Health, Boston, MA, USA.
Received: 18 June 2021 Accepted: 1 October 2021

Published online: 16 October 2021

\section{References}

1. Sung H, Ferlay J, Siegel RL, Laversanne M, Soerjomataram I, Jemal A, Bray F. Global cancer statistics 2020: GLOBOCAN estimates of incidence and mortality worldwide for 36 cancers in 185 countries. CA Cancer J Clin. 2021;71(3):209-49.

2. AIRTUM: The numbers of cancer in Italy-2020. In. https://www.registritumori.it/cms/sites/default/files/pubblicazioni/new_NDC2020-opera tori-web.pdf; 2020

3. Sun YS, Zhao Z, Yang ZN, Xu F, Lu HJ, Zhu ZY, Shi W, Jiang J, Yao PP, Zhu HP. Risk factors and preventions of breast cancer. Int J Biol Sci. 2017;13(11):1387-97.

4. Lei S, Fan P, Wang M, Zhang C, Jiang Y, Huang S, Fang M, He Z, Wu A. Elevated estrogen receptor beta expression in triple negative breast cancer cells is associated with sensitivity to doxorubicin by inhibiting the PI3K/AKT/mTOR signaling pathway. Exp Ther Med. 2020;20(2):1630-6.

5. White AJ, Keller JP, Zhao S, Carroll R, Kaufman JD, Sandler DP. Air pollution, clustering of particulate matter components, and breast cancer in the Sister Study: a U.S. wide cohort. Environ Health Perspect. 2019;127(10):107002.

6. Goldberg MS, Villeneuve PJ, Crouse D, To T, Weichenthal SA, Wall C, Miller $A B$. Associations between incident breast cancer and ambient concentrations of nitrogen dioxide from a national land use regression model in the Canadian National Breast Screening Study. Environ Int. 2019;133(Pt B): 105182.

7. Filippini T, Torres D, Lopes C, Carvalho C, Moreira P, Naska A, Kasdagli MI, Malavolti M, Orsini N, Vinceti M. Cadmium exposure and risk of breast cancer: a dose-response meta-analysis of cohort studies. Environ Int. 2020;142:105879.

8. Gaudet HM, Christensen E, Conn B, Morrow S, Cressey L, Benoit J. Methylmercury promotes breast cancer cell proliferation. Toxicol Rep. 2018;5:579-84.

9. Adani G, Filippini T, Wise LA, Halldorsson TI, Blaha L, Vinceti M. Dietary intake of acrylamide and risk of breast, endometrial, and ovarian cancers: a systematic review and dose-response meta-analysis. Cancer Epidemiol Biomarkers Prev. 2020;29(6):1095-106.

10. IARC working group on the evaluation of carcinogenic risks to humans. Painting, firefighting, and shiftwork. IARC Monogr Eval Carcinog Risks Hum. 2010;98:1-818.

11. Straif K, Baan R, Grosse Y, Secretan B, El Ghissassi F, Bouvard V, Altieri A, Benbrahim-Tallaa L, Cogliano V, WHO International Agency For Research on Cancer Monograph Working Group. Carcinogenicity of shift-work, painting, and fire-fighting. Lancet Oncol. 2007;8(12):1065-6.

12. Papantoniou K, Castano-Vinyals G, Espinosa A, Aragones N, Perez-Gomez B, Ardanaz E, Altzibar JM, Sanchez VM, Gomez-Acebo I, Llorca J, et al. Breast cancer risk and night shift work in a case-control study in a Spanish population. Eur J Epidemiol. 2016;31(9):867-78.

13. IARC working group on the evaluation of carcinogenic hazards to humans. Night shift work. IARC Monogr Eval Carcinog Hazards Hum. 2020;124:1-381.

14. Rumanova VS, Okuliarova M, Zeman M. Differential effects of constant light and dim light at night on the circadian control of metabolism and behavior. Int J Mol Sci. 2020;21(15):5478.

15. Russart KLG, Nelson RJ. Light at night as an environmental endocrine disruptor. Physiol Behav. 2018;190:82-9.

16. Irwin MR, Olmstead R, Carroll JE. Sleep disturbance, sleep duration, and inflammation: a systematic review and meta-analysis of cohort studies and experimental sleep deprivation. Biol Psychiatry. 2016;80(1):40-52.

17. Castanon-Cervantes O, Wu M, Ehlen JC, Paul K, Gamble KL, Johnson RL, Besing RC, Menaker M, Gewirtz AT, Davidson AJ. Dysregulation of inflammatory responses by chronic circadian disruption. J Immunol. 2010;185(10):5796-805.

18. Samuelsson LB, Bovbjerg DH, Roecklein KA, Hall MH. Sleep and circadian disruption and incident breast cancer risk: an evidence-based and theoretical review. Neurosci Biobehav Rev. 2018;84:35-48.

19. McEwen BS, Karatsoreos IN. Sleep deprivation and circadian disruption: stress, allostasis, and allostatic load. Sleep Med Clin. 2015;10(1):1-10. 
20. Cho Y, Ryu SH, Lee BR, Kim KH, Lee E, Choi J. Effects of artificial light at night on human health: a literature review of observational and experimental studies applied to exposure assessment. Chronobiol Int. 2015;32(9):1294-310.

21. Lai KY, Sarkar C, Ni MY, Cheung LWT, Gallacher J, Webster C. Exposure to light at night (LAN) and risk of breast cancer: a systematic review and meta-analysis. Sci Total Environ. 2021;762:143159.

22. Wu Y, Gui SY, Fang Y, Zhang M, Hu CY. Exposure to outdoor light at night and risk of breast cancer: a systematic review and meta-analysis of observational studies. Environ Pollut. 2021;269:116114.

23. Xiao $Q$, James $P$, Breheny P, Jia P, Park Y, Zhang D, Fisher JA, Ward MH, Jones RR. Outdoor light at night and postmenopausal breast cancer risk in the NIH-AARP diet and health study. Int J Cancer. 2020;147(9):2363-72.

24. Clarke RB, Amini H, James P, von Euler-Chelpin M, Jorgensen JT, Mehta A, Cole-Hunter T, Westendorp R, Mortensen LH, Loft S, et al. Outdoor light at night and breast cancer incidence in the Danish Nurse Cohort. Environ Res. 2021;194:110631.

25. Xiao Q, Gierach GL, Bauer C, Blot WJ, James P, Jones RR. The association between outdoor artificial light at night and breast cancer risk in black and white women in the Southern Community Cohort Study. Environ Health Perspect. 2021;129(8):87701.

26. Page MJ, McKenzie JE, Bossuyt PM, Boutron I, Hoffmann TC, Mulrow CD, Shamseer L, Tetzlaff JM, AkI EA, Brennan SE, et al. The PRISMA 2020 statement: an updated guideline for reporting systematic reviews. PLoS Med. 2021;18(3):e1003583.

27. Morgan RL, Whaley P, Thayer KA, Schunemann HJ. Identifying the PECO: A framework for formulating good questions to explore the association of environmental and other exposures with health outcomes. Environ Int. 2018;121(Pt 1):1027-31.

28. European network for Health Technology Assessment (EUnetHTA): Process of information retrieval for systematic reviews and health technology assessments on clinical effectiveness. Version 2.0, December 2019.

29. Morgan RL, Thayer KA, Santesso N, Holloway AC, Blain R, Eftim SE, Goldstone AE, Ross P, Ansari M, Akl EA, et al. A risk of bias instrument for non-randomized studies of exposures: a users' guide to its application in the context of GRADE. Environ Int. 2019;122:168-84.

30. Orsini N, Spiegelman D: Meta-analysis of dose-response relationships. In: Handbook of Meta-Analysis. Edited by Schmid CH, Stijnen T, White I, 1st Edition. New York: Chapman and Hall/CRC; 2021.

31. Filippini T, Hatch EE, Rothman KJ, Heck JE, Park AS, Crippa A, Orsini N, Vinceti M. Association between outdoor air pollution and childhood leukemia: a systematic review and dose-response meta-analysis. Environ Health Perspect. 2019;127(4):46002.

32. Filippini T, Malavolti M, Whelton PK, Naska A, Orsini N, Vinceti M. Blood pressure effects of sodium reduction: dose-response meta-analysis of experimental studies. Circulation. 2021;143(16):1542-67.

33. Vinceti M, Filippini T, Wise LA, Rothman KJ. A systematic review and dose-response meta-analysis of exposure to environmental selenium and the risk of type 2 diabetes in nonexperimental studies. Environ Res. 2021;197:111210.

34. Crippa A, Discacciati A, Bottai M, Spiegelman D, Orsini N. One-stage dose-response meta-analysis for aggregated data. Stat Methods Med Res. 2019;28(5):1579-96

35. De Jong S, Auping WL, Oosterveld WT, Usanov A, Abdalla M, Van de Bovenkamp A, Frattina C: The geopolitical impact of climate mitigation policies: How hydrocarbon exporting rentier states and developing nations can prepare for a more sustainable future. The Hague Centre for Strategic Studies 2017

36. Mohr S, Garland C, Gorham E, Grant W, Highfill R, Garland F: Mapping Vitamin D deficiency, breast cancer, and colorectal cancer. 2005.

37. Egger M, Smith GD, Phillips AN. Meta-analysis: principles and procedures. BMJ. 1997;315(7121):1533-7.

38. Lin L, Shi L, Chu H, Murad MH. The magnitude of small-study effects in the Cochrane Database of Systematic Reviews: an empirical study of nearly 30000 meta-analyses. BMJ Evid Based Med. 2020;25(1):27-32.

39. Duval S, Tweedie RL. A non-parametric "trim and fill" method of accounting for publication bias in meta-analysis. J Am Stat Assoc. 2000;95(449):89-98.

40. Bauer SE, Wagner SE, Burch J, Bayakly R, Vena JE. A case-referent study: light at night and breast cancer risk in Georgia. Int J Health Geogr. 2013;12:23.
41. Garcia-Saenz A, Sanchez de Miguel A, Espinosa A, Valentin A, Aragones N, Llorca J, Amiano P, Martin-Sanchez V, Guevara M, Capelo R et al: Evaluating the association between artificial light-at-night exposure and breast and prostate cancer risk in Spain (MCC-Spain Study). Environ Health Perspect 2018, 126(4):047011.

42. Johns LE, Jones ME, Schoemaker MJ, McFadden E, Ashworth A, Swerdlow AJ. Domestic light at night and breast cancer risk: a prospective analysis of 105000 UK women in the Generations Study. Br J Cancer. 2018;118(4):600-6.

43. Hurley S, Goldberg D, Nelson D, Hertz A, Horn-Ross PL, Bernstein L, Reynolds P. Light at night and breast cancer risk among California teachers. Epidemiology. 2014;25(5):697-706.

44. James P, Bertrand KA, Hart JE, Schernhammer ES, Tamimi RM, Laden F. Outdoor light at night and breast cancer incidence in the Nurses' Health Study II. Environ Health Perspect. 2017;125(8):087010.

45. White AJ, Weinberg CR, Park YM, D'Aloisio AA, Vogtmann E, Nichols HB, Sandler DP. Sleep characteristics, light at night and breast cancer risk in a prospective cohort. Int J Cancer. 2017;141(11):2204-14.

46. Davis S, Mirick DK, Stevens RG. Night shift work, light at night, and risk of breast cancer. J Natl Cancer Inst. 2001;93(20):1557-62.

47. Fritschi L, Erren TC, Glass DC, Girschik J, Thomson AK, Saunders C, Boyle T, El-Zaemey S, Rogers P, Peters S, et al. The association between different night shiftwork factors and breast cancer: a case-control study. Br J Cancer. 2013;109(9):2472-80.

48. Keshet-Sitton A, Or-Chen K, Yitzhak S, Tzabary I, Haim A. Can avoiding light at night reduce the risk of breast cancer? Integr Cancer Ther. 2016;15(2):145-52.

49. Kloog I, Portnov BA, Rennert HS, Haim A. Does the modern urbanized sleeping habitat pose a breast cancer risk? Chronobiol Int. 2011;28(1):76-80.

50. Li Q, Zheng T, Holford TR, Boyle P, Zhang Y, Dai M. Light at night and breast cancer risk: results from a population-based case-control study in Connecticut, USA. Cancer Causes Control. 2010;21(12):2281-5.

51. O'Leary ES, Schoenfeld ER, Stevens RG, Kabat GC, Henderson K, Grimson R, Gammon MD, Leske MC, Electromagnetic Fields and Breast Cancer on Long Island Study Group. Shift work, light at night, and breast cancer on Long Island, New York. Am J Epidemiol. 2006;164(4):358-66.

52. Ritonja J, Mclsaac MA, Sanders E, Kyba CCM, Grundy A, Cordina-Duverger E, Spinelli JJ, Aronson KJ. Outdoor light at night at residences and breast cancer risk in Canada. Eur J Epidemiol. 2020;35(6):579-89.

53. Yang W, Shi Y, Ke X, Sun H, Guo J, Wang X. Long-term sleep habits and the risk of breast cancer among Chinese women: a case-control study. Eur J Cancer Prev. 2019;28(4):323-9.

54. Falchi F, Cinzano P, Duriscoe D, Kyba CC, Elvidge CD, Baugh K, Portnov BA, Rybnikova NA, Furgoni R. The new world atlas of artificial night sky brightness. Sci Adv. 2016;2(6):e1600377.

55. US National Toxicology Program: NTP cancer hazard assessment report on night shift work and light at night. In: NTP Cancer Hazard Assessment Report on Night Shift Work and Light at Night. Research Triangle Park (NC); 2021.

56. Hansen J, Lassen CF. Nested case-control study of night shift work and breast cancer risk among women in the Danish military. Occup Environ Med. 2012;69(8):551-6.

57. Hansen J, Stevens RG. Case-control study of shift-work and breast cancer risk in Danish nurses: impact of shift systems. Eur J Cancer. 2012;48(11):1722-9.

58. Lie JA, Kjuus H, Zienolddiny S, Haugen A, Stevens RG, Kjaerheim K. Night work and breast cancer risk among Norwegian nurses: assessment by different exposure metrics. Am J Epidemiol. 2011;173(11):1272-9.

59. Megdal SP, Kroenke CH, Laden F, Pukkala E, Schernhammer ES. Night work and breast cancer risk: a systematic review and meta-analysis. Eur J Cancer. 2005;41(13):2023-32.

60. Pukkala E, Helminen M, Haldorsen T, Hammar N, Kojo K, Linnersjo A, Rafnsson V, Tulinius H, Tveten U, Auvinen A. Cancer incidence among Nordic airline cabin crew. Int J Cancer. 2012;131(12):2886-97.

61. Costa G, Haus E, Stevens R. Shift work and cancer - considerations on rationale, mechanisms, and epidemiology. Scand J Work Environ Health. 2010;36(2):163-79.

62. Haus EL, Smolensky MH. Shift work and cancer risk: potential mechanistic roles of circadian disruption, light at night, and sleep deprivation. Sleep Med Rev. 2013;17(4):273-84. 
63. Touitou Y, Reinberg A, Touitou D. Association between light at night, melatonin secretion, sleep deprivation, and the internal clock: health impacts and mechanisms of circadian disruption. Life Sci. 2017;173:94-106.

64. Erren TC, Reiter RJ, Piekarski C. Light, timing of biological rhythms, and chronodisruption in man. Naturwissenschaften. 2003;90(11):485-94.

65. Herljevic M, Middleton B, Thapan K, Skene DJ. Light-induced melatonin suppression: age-related reduction in response to short wavelength light. Exp Gerontol. 2005;40(3):237-42.

66. Stevens RG, Rea MS. Light in the built environment: potential role of circadian disruption in endocrine disruption and breast cancer. Cancer Causes Control. 2001;12(3):279-87.

67. Garland CF, Garland FC. Do sunlight and vitamin D reduce the likelihood of colon cancer? Int J Epidemiol. 1980:9(3):227-31.

68. Moukayed M, Grant WB. The roles of UVB and vitamin D in reducing risk of cancer incidence and mortality: a review of the epidemiology, clinical trials, and mechanisms. Rev Endocr Metab Disord. 2017;18(2):167-82.

69. Altieri B, Grant WB, Della Casa S, Orio F, Pontecorvi A, Colao A, Sarno G, Muscogiuri G. Vitamin D and pancreas: the role of sunshine vitamin in the pathogenesis of diabetes mellitus and pancreatic cancer. Crit Rev Food Sci Nutr. 2017:57(16):3472-88

70. Chen W, Clements M, Rahman B, Zhang S, Qiao Y, Armstrong BK. Relationship between cancer mortality/incidence and ambient ultraviolet $B$ irradiance in China. Cancer Causes Control. 2010;21(10):1701-9.

71. Ong JS, Cuellar-Partida G, Lu Y, Australian Ovarian Cancer S, Fasching PA, Hein A, Burghaus S, Beckmann MW, Lambrechts D, van Nieuwenhuysen E et al: Association of vitamin D levels and risk of ovarian cancer: a Mendelian randomization study. Int J Epidemiol 2016, 45(5):1619-1630.

72. Grant WB. Low ultraviolet-B exposure may explain some of the link between night shift work and increased risk of prostate cancer. Int J Cancer. 2015;137(4):999.

73. IARC working group on the evaluation of carcinogenic risks to humans. Solar and ultraviolet radiation. IARC Monogr Eval Carcinog Risks Hum. 2012;100D:35-101.

74. Holick MF. Biological effects of sunlight, ultraviolet radiation, visible light, infrared radiation and vitamin D for health. Anticancer Res. 2016;36(3):1345-56.

75. Hancock AM, Witonsky DB, Alkorta-Aranburu G, Beall CM, Gebremedhin A, Sukernik R, Utermann G, Pritchard JK, Coop G, Di Rienzo A. Adaptations to climate-mediated selective pressures in humans. PLoS Genet. 2011;7(4):e1001375.

76. Kyriacou CP, Peixoto AA, Sandrelli F, Costa R, Tauber E. Clines in clock genes: fine-tuning circadian rhythms to the environment. Trends Genet. 2008;24(3):124-32.
77. Johnsen A, Fidler AE, Kuhn S, Carter KL, Hoffmann A, Barr IR, Biard C, Charmantier A, Eens M, Korsten P, et al. Avian Clock gene polymorphism: evidence for a latitudinal cline in allele frequencies. Mol Ecol. 2007;16(22):4867-80.

78. O'Malley KG, Banks MA. A latitudinal cline in the Chinook salmon (Oncorhynchus tshawytscha) Clock gene: evidence for selection on PolyQ length variants. Proc Biol Sci. 2008;275(1653):2813-21.

79. Forni D, Pozzoli U, Cagliani R, Tresoldi C, Menozzi G, Riva S, Guerini FR, Comi GP, Bolognesi E, Bresolin N, et al. Genetic adaptation of the human circadian clock to day-length latitudinal variations and relevance for affective disorders. Genome Biol. 2014;15(10):499.

80. Putilov AA, Dorokhov VB, Poluektov MG. How have our clocks evolved? Adaptive and demographic history of the out-of-African dispersal told by polymorphic loci in circadian genes. Chronobiol Int. 2018;35(4):511-32.

81. Hancock AM, Alkorta-Aranburu G, Witonsky DB, Di Rienzo A. Adaptations to new environments in humans: the role of subtle allele frequency shifts. Philos Trans R Soc Lond B Biol Sci. 2010;365(1552):2459-68.

82. Stanhope J, Liddicoat C, Weinstein P. Outdoor artificial light at night: a forgotten factor in green space and health research. Environ Res. 2021;1:111012

83. Huss A, van Wel L, Bogaards L, Vrijkotte T, Wolf L, Hoek G, Vermeulen R. Shedding some light in the dark-a comparison of personal measurements with satellite-based estimates of exposure to light at night among children in the Netherlands. Environ Health Perspect. 2019;127(6):67001.

84. Jones RR. Exposure to artificial light at night and risk of cancer: where do we go from here? Br J Cancer. 2021;124(9):1467-8.

85. Helbich M, Browning M, Huss A. Outdoor light at night, air pollution and depressive symptoms: a cross-sectional study in the Netherlands. Sci Total Environ. 2020;744:140914.

86. Munzel T, Hahad O, Daiber A. The dark side of nocturnal light pollution. Outdoor light at night increases risk of coronary heart disease. Eur Heart J. 2021:42(8):831-4.

87. Walker WH 2nd, Bumgarner JR, Walton JC, Liu JA, Melendez-Fernandez $\mathrm{OH}$, Nelson RJ, DeVries AC. Light pollution and cancer. Int J Mol Sci. 2020;21(24):9360

\section{Publisher's Note}

Springer Nature remains neutral with regard to jurisdictional claims in published maps and institutional affiliations.

Ready to submit your research? Choose BMC and benefit from:

- fast, convenient online submission

- thorough peer review by experienced researchers in your field

- rapid publication on acceptance

- support for research data, including large and complex data types

- gold Open Access which fosters wider collaboration and increased citations

- maximum visibility for your research: over $100 \mathrm{M}$ website views per year

At BMC, research is always in progress.

Learn more biomedcentral.com/submissions 